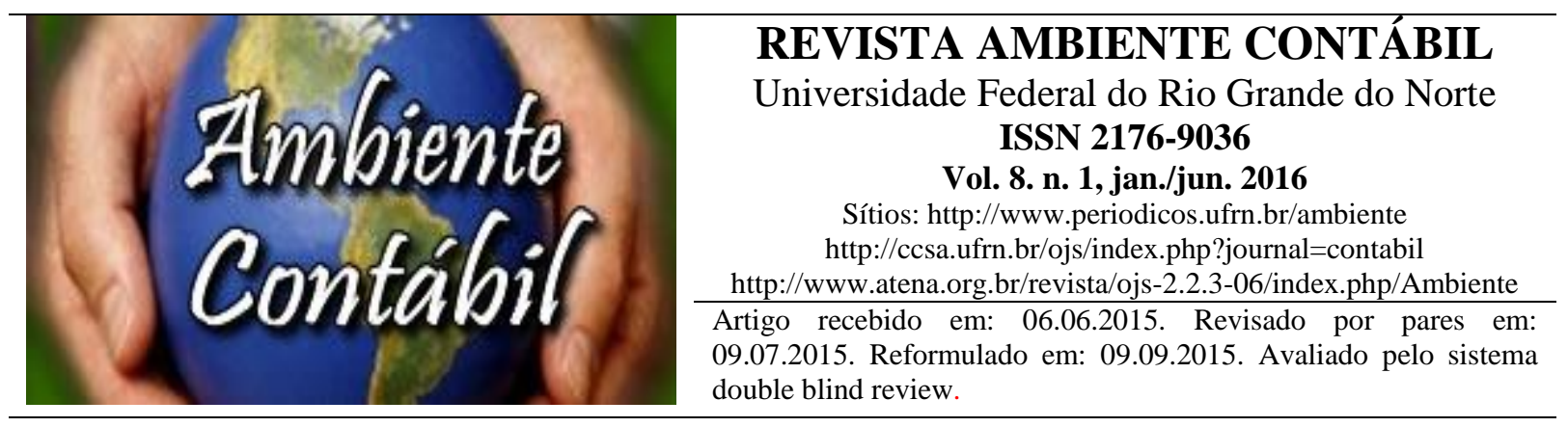

\title{
PRÁTICAS GERENCIAIS DE MICRO E PEQUENAS EMPRESAS
}

\section{MANAGEMENT PRACTICES OF MICRO AND SMALL COMPANIES}

\section{PRÁCTICAS DE GESTIÓN DE MICRO Y PEQUEÑAS EMPRESAS}

\section{Autores}

\section{Vanderlei dos Santos}

Doutorando do Programa de Pós-Graduação em Contabilidade da

Universidade Federal de Santa Catarina - UFSC. Professor da Universidade do Estado de Santa Catarina - UDESC. Endereço: Universidade Federal de Santa Catarina, Campus Reitor João David Ferreira Lima, s/n, Bairro Trindade. CEP 88040-900 - Florianópolis, SC - Brasil

Telefone: 55 (48) 3721-6608

E-mail: vanderleidossantos09@gmail.com

\section{Diego Roberto Dorow}

Bacharel em Ciências Contábeis pela Universidade do Estado de Santa Catarina - UDESC. Endereço: Rua Dr. Getúlio Vargas, 2822 - Bairro Bela Vista. CEP 89140-000 - Ibirama, SC

- Brasil. Telefone: 55 (47) 3357-3077

E-mail: diego.dorow@hotmail.com

\section{Ilse Maria Beuren}

Doutora em Controladoria e Contabilidade pela FEA/USP. Professora do Programa de PósGraduação em Contabilidade da Universidade Federal de Santa Catarina - UFSC. Endereço: Universidade Federal de Santa Catarina, Campus Reitor João David Ferreira Lima, s/n, Bairro Trindade. CEP 88040-970 - Florianópolis, SC - Brasil. Telefone: 55 (48) 3721-6608 E-mail: ilse.beuren@gmail.com

\section{RESUMO}

O estudo investiga quais são os instrumentos e procedimentos gerenciais utilizados em micro e pequenas empresas na tomada de decisão. Pesquisa descritiva com abordagem quantitativa foi realizada por meio de levantamento, tendo como amostra as 41 empresas respondentes do questionário. A análise dos dados foi realizada com aplicação de estatística descritiva, entropia informacional e o teste Mann-Whitney U. Os resultados mostram que nas empresas pesquisadas a tomada de decisão é baseada na experiência do proprietário. As empresas têm conhecimento do resultado mensal, mas não o discutem com o seu contador. A maioria das empresas não utiliza a contabilidade na tomada de decisão, seja pelo fato da informação contábil não refletir a real situação da empresa e/ou o gestor desconhecer sua utilidade. Os 
instrumentos gerenciais mais utilizados na tomada de decisão são controles operacionais e planejamento tributário, e os menos utilizados são demonstrações contábeis, métodos de custeio e outros instrumentos gerenciais. A maioria destas empresas não conhece ou não faz uso de instrumentos que orientam as estratégias e ações organizacionais, como o planejamento estratégico e o orçamento.

Palavras-chave: Instrumentos gerenciais. Procedimentos gerenciais. Tomada de decisão. Micro e pequenas empresas.

\begin{abstract}
The study investigates which instruments and management procedures are used in micro and small companies in decision making. Descriptive research with quantitative approach was conducted through survey, with a sample of 41 companies. Data analysis was performed with the application of descriptive statistics, informational entropy and Mann-Whitney U test. The results show that, in the companies surveyed, the decision making is based on the owner's experience. Companies are aware of the monthly result, but it is not discussed with the accountant. Most companies do not use the accounting in the decision making, either because the accounting information does not reflect the real situation of the company, and/or the manager is not familiar with its usefulness. The most used management tools in decision making are operating controls and tax planning, and the least used are financial statements, costing methods and other management tools. Most of these companies do not know or makes no use of instruments which guide the strategies and organizational actions, such as strategic planning and budget.
\end{abstract}

Keywords: Management instruments. Management procedures. Decision making. Micro and small businesses.

\title{
RESUMEN
}

El estudio investiga cuáles son los instrumentos y procedimientos de gestión utilizados en micro y pequeñas empresas en la toma de decisiones. La investigación descriptiva con enfoque cuantitativo se llevó a cabo a través de la encuesta, con una muestra de 41 empresas que respondieron la encuesta. El análisis de datos se realizó con la aplicación de la estadística descriptiva, la entropía informacional y la prueba de Mann-Whitney U. Los resultados muestran que en las empresas encuestadas la toma de decisiones se basa en la experiencia del usuario. Las empresas son conscientes del resultado mensual, pero no se discute con su contador. La mayoría de las empresas no utilizan la contabilidad en la toma de decisiones, ya sea porque a la información contable no refleja la situación real de la empresa y/o el gestor no está familiarizado con su utilidad. Los instrumentos de gestión más utilizados en la toma de decisiones son controles operacionales y la planificación fiscal, y los menos utilizados son los estados financieros, los métodos de costeo y otros instrumentos de gestión. La mayoría de estas empresas no sabe o no hace uso de instrumentos que guían las estrategias y acciones de la organización, como la planificación estratégica y el presupuesto.

Palabras clave: Instrumentos de gestión. Procedimientos de gestión. La toma de decisiones. Micro y pequeñas empresas.

\section{INTRODUÇÃO}

As empresas competem em um mercado que apresenta constantes mudanças, o que requer informações oportunas e controle de seu negócio para adequar suas operações às novas condições do mercado. A tomada de decisão não pode ser apenas baseada na intuição ou experiência do gestor. São necessários instrumentos que forneçam informações confiáveis, fidedignas e oportunas para auxiliar no processo decisório. 
A contabilidade gerencial, além de fornecer aos gestores informações que os auxiliam nas suas funções gerenciais, contribui para assegurar a sobrevivência da organização, em função de identificar e analisar os seus eventos econômicos e do seu entorno (ATKINSON et al., 2008). Um dos principais objetivos da informação contábil é contribuir para a tomada de decisão. Essas informações são necessárias para todo tipo de organização, inclusive nas micro e pequenas empresas.

Entretanto, essas empresas têm enfrentado dificuldades na administração e controle de seus negócios, levando-as à mortalidade precoce. Destacam-se como fatores condicionantes à mortalidade das pequenas empresas, problemas particulares dos sócios, crise econômica, ambiente de negócios desfavorável, forte concorrência e alta carga tributária (SALES; BARROS; PEREIRA, 2011). A falta de utilização de informações contábeis e a ausência de assistência ou assessoria de um contador foram apontadas por Sales, Barros e Pereira (2011) como fatores condicionantes à mortalidade precoce de pequenos empreendimentos. Portanto, não basta que as informações sejam produzidas, é necessário que cheguem à pessoa certa, no formato desejado e no momento oportuno.

Presume-se que tais dificuldades e problemas poderiam ser minimizados se houvesse maior utilização de instrumentos gerenciais em micro e pequenas empresas. Ruengdet e Wongsurawat (2010) identificaram cinco determinantes para o sucesso de micro e pequenas empresas comunitárias tailandesas: a) membros para dirigir a propriedade do negócio; b) divisão sistemática do trabalho; c) registros contábeis regulares; d) planos de marketing inteligentes; e) obtenção de algum tipo de certificação de qualidade.

Estudo realizado por Faria, Azevedo e Oliveira (2012) identificou que há uma subutilização dos instrumentos contábeis nessas empresas, em decorrência de seus gestores desconhecerem ou não estarem convencidos da utilidade da contabilidade no processo de gestão. Queiroz (2005) realizou pesquisa com micro e pequenas empresas na região do Seridó Potiguar, RN, e identificou que $69,1 \%$ utilizam a informação contábil somente para o cumprimento das obrigações fiscais e trabalhistas, e apenas $42,6 \%$ a utilizam como apoio à tomada de decisão.

A descrença que os gestores têm na informação contábil pode ser justificada pelo relacionamento das empresas com as prestadoras de serviços contábeis, muitas vezes utilizadas apenas para atendimento das obrigações legais, como evidenciado nos estudos de Pires, Costa e Hahn (2004) e Santana et al. (2007). A falta de instrumentos gerenciais nas micro, pequenas e médias empresas, conforme Kassai (1997), decorre do fato que, na maioria das vezes, a tomada de decisão tem como base a intuição ou mesmo a improvisação.

Assim, evidencia-se uma lacuna relativa ao uso de instrumentos da contabilidade gerencial em micro e pequenas empresas e que instiga a realização de pesquisas sobre sua utilização como base para a tomada de decisão. Estudos sobre instrumentos gerenciais geralmente são direcionadas às empresas de grande porte, como de Chenhall e LangfieldSmith (1998), Frezatti (2005), Oyadomari et al. (2008), Guerreiro, Cornachione Júnior e Soutes (2011), Frezatti et al. (2012).

Neste sentido, focaliza-se no estudo a seguinte questão de pesquisa: Quais são os instrumentos e procedimentos gerenciais utilizados pelas micro e pequenas empresas na tomada de decisão, em específico, controles operacionais, demonstrações contábeis, métodos de custeio e artefatos gerenciais? Assim, o objetivo desta pesquisa é investigar quais são os instrumentos e procedimentos gerenciais utilizados pelas micro e pequenas empresas na tomada de decisão. De forma complementar, busca-se verificar o grau de importância atribuído pelos gestores aos instrumentos da contabilidade gerencial para a tomada de decisão.

Shahabi, Hosseinpour e Soheila (2014) destacam que as pequenas e médias empresas (PME) são relevantes para o desenvolvimento econômico da maioria dos países em 
desenvolvimento, uma vez que contribuem para a geração de receitas públicas por meio de pagamento de tributos e proporcionam lucros, dividendos e salários às famílias. No aspecto social, impulsionam a redução da pobreza pelas transferências financeiras e rendimentos do trabalho e de propriedade da empresa.

As micro e pequenas empresas ao longo dos anos também se tornaram fortes ícones na economia brasileira, sendo responsáveis pela maior parte dos empregos formais, distribuição de renda, arrecadação de tributos, desenvolvimento de regiões, entre outros fatores que movimentam a economia e aumentam o Produto Interno Bruto (PIB) brasileiro (SEBRAE, 2007; 2011; 2013). Porém, a falta de aprimoramento dos gestores e conhecimento de instrumentos gerenciais tem contribuído para inibir o crescimento destas empresas, pois o gerenciamento nessas organizações geralmente é realizado de forma intuitiva. Também são poucas as empresas que se utilizam da análise de dados como apoio ao planejamento e à tomada de decisão (LIMA; IMONIANA, 2008).

Sales, Barros e Pereira (2011) apontam que a falta do uso de informações contábeis e ausência de assistência ou assessoria de um contador são fatores condicionantes à mortalidade precoce de pequenos empreendimentos. Nesse sentido, a pesquisa pode contribuir para as prestadoras de serviços contábeis na sua relação com o cliente, ofertando serviços mais alinhados. Os resultados do estudo ainda podem indicar informações contábeis mais úteis ao processo decisório nas micro e pequenas empresas.

\section{REVISÃO BIBLIOGRÁFICA}

\subsection{INSTRUMENTOS E PROCEDIMENTOS GERENCIAIS}

A contabilidade gerencial tem o propósito de fornecer informações aos gestores para que possam utilizá-las na tomada de decisão (HORNGREN; SUNDEM; STRATTON, 2004; ATKINSON et al., 2008). Contudo, a contabilidade não se caracteriza somente como um meio gerador de informações, permite explicar fenômenos patrimoniais, efetuar análises, controlar, prever e projetar resultados futuros, entre outras funções (SANTOS et al., 2014). Todas as empresas necessitam de informações contábeis gerenciais para administrar seu negócio, inclusive as micro e pequenas empresas.

O Pronunciamento International Management Accounting Practice 1 define a contabilidade gerencial como sendo uma atividade que envolve parceria na gestão, auxiliando na elaboração de sistemas de gestão de desempenho, no planejamento, na tomada de decisão e fornecendo análise de relatórios financeiros e de controle para auxiliar na gestão e na formulação e implementação da estratégia (ABDEL-KADER; LUTHER, 2006).

Para Horngren, Sundem e Stratton (2004, p. 4), “a contabilidade gerencial é o processo de identificar, mensurar, acumular, analisar, preparar, interpretar e comunicar informações que auxiliem os gestores a atingir objetivos organizacionais". De modo abrangente, a contabilidade gerencial pode ser caracterizada como a união de várias técnicas e procedimentos contábeis já conhecidos na contabilidade financeira, na contabilidade de custos, na análise financeira e de balanços, porém colocados em outra perspectiva, em um formato mais analítico, de modo a auxiliar seus usuários internos (IUDÍCIBUS, 1998).

$\mathrm{Na}$ contabilidade gerencial, o termo artefato é utilizado para designar "atividades, ferramentas, filosofias de gestão, instrumentos, métodos de custeio, modelos de gestão, métodos de avaliação ou sistemas de custeio que possam ser utilizados pelos profissionais da contabilidade no exercício de suas funções" (SOUTES, 2006, p. 23). Frezatti et al. (2009) afirmam que os artefatos correspondem a todos os instrumentos e técnicas empregados para suportar a gestão das entidades. "Espera-se que a existência e a utilização dos artefatos permitam maiores chances de sucesso organizacional" (FREZATTI et al. 2012, p. 142). 
Pesquisas sobre a utilização dos instrumentos gerenciais vêm sendo realizadas periodicamente, envolvendo objetos de estudos específicos e amostras diferenciadas. Sulaiman, Ahmad e Alwi (2004) investigaram o uso de artefatos gerencias em quatro países asiáticos, separando-os em tradicionais e modernos. Observaram que a utilização dos artefatos modernos nos quatro países pesquisados ainda era embrionária. Foram considerados modernos os seguintes instrumentos: Custeio Baseado em Atividades (ABC), Custeio Meta, Balanced Scorecard (BSC) e Gestão da Qualidade Total.

Frezatti (2005) investigou o nível de aderência que as empresas brasileiras de médio e grande porte têm com o arcabouço teórico dos elementos da contabilidade gerencial. Observou que a economia brasileira é composta de organizações que estão vivendo diferentes estágios da contabilidade gerencial, e que essas diferenças são significativas. Nenhuma associação entre setor econômico e agrupamento foi encontrada na análise, diferentemente do tamanho, em que constatou maior aderência em organizações de maior porte.

Oyadomari et al. (2008) buscaram identificar os fatores que influenciam a decisão de adotar artefatos de controle gerencial em 27 empresas brasileiras, à luz da Teoria NeoInstitucional. Os resultados revelaram que há uma adoção do tipo cerimonial na implementação dos artefatos. O mecanismo mimético é o mais importante na adoção dos mesmos. A obtenção do conhecimento sobre novos artefatos ocorre, preponderantemente, pela socialização do conhecimento, por meio de seminários, visitas a outras empresas, consultorias e notícias de jornais e revistas de negócios. As consultorias têm papel importante na adoção dos artefatos.

Guerreiro, Cornachione Júnior e Soutes (2011) verificaram se empresas brasileiras de uma amostra selecionada, que se destacam pelo seu porte na economia brasileira, utilizam artefatos modernos de contabilidade gerencial. Os resultados mostraram que as empresas da amostra estudada utilizam artefatos modernos de contabilidade gerencial. A intensidade da utilização varia de artefato para artefato e mesmo os artefatos com menor uso, tais como Just in Time, Kaizen e Target Costing são empregados por mais de $30 \%$ das empresas estudadas.

Oyadomari et al. (2011) averiguaram os relacionamentos entre o uso do sistema de controle gerencial e as competências organizacionais em empresas brasileiras de grande porte. Não observaram evidências de relacionamento negativo entre uso diagnóstico e o desenvolvimento de competências organizacionais. Porém, constataram que o uso interativo influencia positivamente as competências de aprendizagem organizacional e de orientação para mercado e estas influenciam positivamente o desempenho.

Frezatti et al. (2012) analisaram a associação entre atributos do sistema de controle gerencial (escopo, tempestividade, agregação e integração) e o perfil de artefatos do sistema de informações gerenciais de 125 empresas brasileiras de médio e grande porte. Observaram que os atributos se relacionam de maneira diferenciada, dependendo do perfil do escopo da organização, influenciando a existência de alguns artefatos da contabilidade gerencial. O escopo afeta principalmente os instrumentos mais abrangentes de planejamento (planejamento estratégico e orçamento de capital). A integração influencia a adoção do rolling forecast, instrumento auxiliar a outro mais estruturado e mais rígido (o orçamento). A tempestividade se mostrou relevante como fator limitativo ao planejamento estratégico, inibindo-o no perfil de escopo amplo e na análise de lucratividade.

\subsection{PRÁTICAS GERENCIAIS EM MICRO E PEQUENAS EMPRESAS}

Observa-se na literatura que as micro e pequenas empresas têm como característica a quase total ausência de instrumentos gerenciais, baseando a tomada de decisão na experiência, intuição e improvisação dos gestores (LACERDA, 2006). Leone (1999, p. 93) afirma que "durante muito tempo pensou-se que as pequenas e médias empresas deveriam utilizar, em 
menor escala, os mesmos princípios de administração usados pelas grandes empresas". Entretanto, o autor salienta que estas empresas necessitam de enfoque distinto, pois têm seus próprios problemas e são caracterizadas por extrema heterogeneidade.

Os proprietários das pequenas empresas atribuem à contabilidade o excesso de burocracia e a arrecadação de tributos. Justifica-se este pensamento em função de que os gestores dos escritórios de contabilidade procuram especializar-se nos aspectos fiscais e oferecer auxílio nessa área, deixando de fornecer informações relativas à gestão da empresa. As prestadoras de serviços contábeis disponibilizam informações que dão suporte à tomada de decisão, especificamente no que concerne à parte fiscal do negócio. Queiroz (2005) constatou que as informações contábeis oferecidas pelas prestadoras de serviços contábeis são de cunho fiscal e trabalhista.

Bernardes e Miranda (2011) também constataram em seu estudo que as prestadoras de serviços contábeis oferecem serviços relacionados apenas aos trâmites legais e burocráticos, e que o contador só é procurado para atender esses tipos de serviços. Segundo esses autores, o gestor não percebe o contador como profissional capaz de ajudá-lo a administrar o seu negócio. Por outro lado, não se percebe interesse dos profissionais contábeis em atualizar-se e colocar em prática um posicionamento além dos assuntos fiscais da empresa. Para Caneca et al. (2009), os contadores que oferecem serviços relacionados à contabilidade gerencial têm mais chances de satisfazer seus clientes e obter vantagem competitiva.

A contabilidade gerencial tem importância na gestão do empreendimento, logo precisa receber a atenção correspondente. Souza (2008) apresenta duas razões para a contabilidade gerencial não receber a devida atenção. A primeira, é que a informação se destina aos proprietários, e muitas vezes estes não se dispõem a criar uma estrutura que permita gerar informações gerenciais. A segunda razão, é que a maioria dos sistemas de informações gerenciais costuma ser mantida em funcionamento por um longo período de tempo, não permitindo que a implantação de um novo sistema proporcione melhores condições de gestão.

Estudos sobre instrumentos gerenciais também abarcaram as micro e pequenas empresas, tanto em nível internacional como nacional. Em âmbito internacional pode-se citar os estudos realizados por Ekanem (2005), Perera e Baker (2007), Ruengdet e Wongsurawat (2010), Lohr (2012) e Švárová e Vrchota (2013).

Ekanem (2005) investigou como as decisões de investimento são realizadas em oito pequenas empresas e o argumento central foi que estas empresas usam técnicas bootstrapping em detrimento de métodos formais sugeridos na literatura de gestão financeira. Bootstrapping representa uma abordagem à tomada de decisões que se baseia na experiência anterior dos tomadores de decisão. Bootstrapping é uma forma de comportamento de aprendizagem que engloba conhecimentos, habilidades, valores e atitudes e fornece aos proprietários-gerentes uma oportunidade para avaliar os resultados com base na experiência anterior. Observou que nenhuma das empresas do estudo multicasos utilizou quaisquer métodos convencionais de processo de tomada de decisão de investimentos e que os proprietários-gerentes encontravam sua própria solução para um problema, conceituada como bootstrapping.

Perera e Baker (2007) examinaram o uso de medidas de desempenho financeiras e não financeiras em pequenas e médias empresas industriais (PMEs) da Austrália. Os resultados apontaram que as PMEs atribuem maior ênfase às medidas financeiras, mas com aumento no tamanho há uma tendência de uso de medidas não financeiras. Além disso, as PMEs com gestores não proprietários utilizam mais medidas de desempenho não financeiras do que aquelas que possuem o proprietário como gestor. Ainda foi observado que para fins de planejamento e controle, as PMEs utilizam informações geradas a partir de sistemas de medição de desempenho em graus variados.

Ruengdet e Wongsurawat (2010) investigaram as características predominantes que diferenciam as micro e pequenas empresas bem-sucedidas e as consideradas sem êxito, sendo 
57 consideradas de sucesso pelo governo da Tailândia e 37 sem êxito. Os resultados mostraram que as empresas bem-sucedidas são mais propensas a ter uma divisão clara e sistemática do trabalho. Constataram ainda que manter o controle de informações por meio de registros contábeis regulares é crucial para o sucesso do negócio, principalmente no que envolve transações de custos e despesas. Foram também considerados como determinantes a elaboração de planos de marketing e a obtenção de certificado de qualidade.

Lohr (2012) realizou um estudo de caso em cinco pequenas e médias empresas industriais alemãs e constatou que as atividades da contabilidade gerencial são limitadas nestas empresas por dois motivos principais: (1) os benefícios não compensam os custos associados; e (2) a posição de mercado da empresa tem sido historicamente forte, sem contabilidade gerencial. No entanto, os estudos de caso também revelaram tendências de que algumas dessas empresas poderão implementar a contabilidade gerencial no futuro.

Švárová e Vrchota (2013) relacionaram a gestão estratégica com o sucesso financeiro de pequenas e médias empresas da República Checa. Os dados foram coletados em uma amostra de 176 empresas. Os resultados da pesquisa revelaram que as PMEs com uma estratégia claramente definida apresentaram melhores resultados de saúde financeira comparativamente com empresas sem uma estratégia definida.

Em âmbito nacional, destacam-se os estudos sobre instrumentos gerenciais em micro e pequenas empresas realizados por Silva et al. (2010), Carvalho e Lima (2011) e Anjos et al. (2012). Silva et al. (2010) identificaram a forma como a informação contábil é utilizada pelas micro e pequenas empresas. Os resultados mostraram que, independente do tamanho, quase a totalidade das empresas conta com serviços de um profissional de contabilidade e que as demonstrações mais frequentemente disponibilizadas pelos profissionais são as mais conhecidas e menos sofisticadas.

Carvalho e Lima (2011) analisaram as práticas gerenciais utilizadas pelas micro e pequenas empresas do setor de confecções da cidade de Sousa/PB. Os resultados apontaram que os gestores dessas empresas utilizam de maneira informal os controles internos para a tomada de decisões, como o controle de contas a pagar, controle de caixa e controle de contas a receber. Anjos et al. (2012) investigaram como os micro e pequenos empresários percebem a utilidade da informação contábil na obtenção de crédito junto aos bancos. Os resultados evidenciaram que o uso da informação contábil ou consulta ao contador externo à empresa é percebida como útil, com destaque para aquelas empresas que têm gestores com mais experiência no negócio ou com maior grau de escolaridade.

\section{MÉTODO E PROCEDIMENTOS DA PESQUISA}

\subsection{POPULAÇÃO E AMOSTRA}

A população da pesquisa compreendeu as micro, pequenas e médias empresas do Alto Vale do Itajaí, SC, Brasil. O contato com as empresas buscou-se junto aos acadêmicos do curso de Ciências Contábeis de uma Instituição de Ensino Superior e com os escritórios de contabilidade da região. Desses contatos, obteve-se um total de 216 empresas, representando a população do estudo.

O questionário foi encaminhado por e-mail para estas empresas, solicitando que o mesmo fosse direcionado ao seu gestor. Após tentativas via e-mail e telefone, obteve-se resposta de 46 empresas, constituindo, assim, uma amostra por acessibilidade. Dessas empresas, foram excluídas cinco, tendo como critério que o respondente não poderia ocupar o cargo de auxiliar, mas sim, de gestor ou outro cargo de gestão das empresas. Desse modo, a amostra final compreendeu os 41 respondentes. 


\subsection{INSTRUMENTO DA PESQUISA}

O questionário foi dividido em quatro partes conforme consta no Apêndice deste artigo. A primeira para obter informações sobre a empresa e o respondente, a segunda para identificar os procedimentos utilizados pelos gestores no processo de decisão, a terceira para averiguar os instrumentos gerenciais utilizados pelas empresas e a quarta para atribuir o grau de importância destes instrumentos conforme a percepção dos gestores.

A segunda parte do instrumento, que buscou identificar os procedimentos de tomada de decisão das micro e pequenas empresas, compõe-se de 13 assertivas sobre quem exerce o comando da empresa, o recurso utilizado para a tomada de decisão, se o empresário possui conhecimento do resultado mensal da empresa e se este resultado é discutido com o contador, fontes de consulta para a tomada de decisões financeiras, responsável pelo setor financeiro e de produção, sistemas utilizados na elaboração de relatórios para a tomada de decisão. Essas questões foram extraídas e adaptadas dos estudos de Pires, Costa e Hahn (2004), Correia (2010), Panucci Filho e Almeida (2011), Anjos et al. (2012), Faria, Azevedo e Oliveira (2012) e Moreira et al. (2013).

A terceira parte do questionário buscou identificar os instrumentos gerenciais utilizados pelas empresas no processo decisório. Os instrumentos foram segregados em controles operacionais, demonstrações contábeis, métodos de custeio e outros artefatos da contabilidade gerencial. Os controles operacionais foram extraídos do estudo de Lima (2007); as demonstrações contábeis foram as mesmas consideradas por Stroeher e Freitas (2008) e Faria, Azevedo e Oliveira (2012); os métodos de custeio e os outros artefatos da contabilidade gerencial foram extraídos dos estudos de Soutes (2006) e Panucci Filho e Almeida (2011). Neste bloco, os respondentes foram solicitados a indicar se utilizam os instrumentos elencados, com as seguintes opções: sim, utilizo na tomada de decisão; conheço, mas não utilizo na tomada de decisão; e não conheço o instrumento de contabilidade gerencial.

Nesta pesquisa, consideraram-se os seguintes controles operacionais: controle de caixa, controle de contas a pagar, controle de contas a receber, controle de estoques e controle de custos e despesas. Como demonstrações e relatórios contábeis consideraram-se: Balancete de verificação, Balanço Patrimonial (BP) e Demonstração do Resultado (DRE), Demonstração das Mutações do Patrimônio Líquido (DMPL) ou Demonstração dos Lucros ou Prejuízos Acumulados (DLPA), Demonstração dos Fluxos de Caixa (DFC), Demonstração do Valor Adicionado (DVA), Notas Explicativas (NEs). Ao passo que o custeio por absorção, custeio variável, custeio padrão, custeio $\mathrm{ABC}$ e custo meta representam os métodos de custeio investigados. Em outros artefatos gerenciais foram considerados o planejamento estratégico, orçamento, planejamento tributário, retorno sobre investimento e ponto de equilíbrio.

Por fim, o quarto bloco do instrumento focalizou o grau de importância dos instrumentos gerenciais na tomada de decisão das micro, pequenas e médias empresas. Para a classificação do grau de importância dos instrumentos gerenciais, utilizou-se a escala Likert de cinco pontos: (1) nada importante, (2) pouco importante, (3) indiferente, (4) importante e (5) muito importante.

O questionário foi encaminhado para seis micro e pequenas empresas para que estas pudessem respondê-lo na forma de um pré-teste do instrumento. Estas empresas foram selecionadas por acessibilidade e o contato foi obtido por meio de acadêmicos do curso de Ciências Contábeis de uma Instituição de Ensino Superior. Após isso, o instrumento passou por alguns ajustes de redação para torna-lo mais inteligível aos respondentes. 


\subsection{PROCEDIMENTOS DE ANÁLISE DOS DADOS}

$\mathrm{Na}$ análise dos dados, utilizaram-se técnicas de estatística descritiva nos dados demográficos das empresas e dos respondentes, nos procedimentos adotados na tomada de decisão e na utilização dos instrumentos gerenciais. Por sua vez, a entropia informacional foi aplicada para analisar o grau de importância atribuído pelos gestores aos instrumentos gerenciais indicados no instrumento de pesquisa.

A entropia representa uma medida da quantidade de informação, aplicável para avaliar situações em que há diferentes respostas (ZELENY, 1982). Segundo o autor, as respostas são medidas a partir de um ponto de referência, assim cada resposta terá uma probabilidade dentro de um conjunto, de modo que respostas idênticas as esperadas não representem surpresas. As que surpreendem, por estarem distantes do que era esperado, avaliam a quantidade de informação contida em uma pergunta ou em um conjunto de perguntas. A fórmula para calcular a entropia da informação seguiu os passos definidos por Zeleny (1982).

Por último, o teste não-paramétrico Mann-Whitney U foi aplicado para analisar se o uso de determinados procedimentos na tomada de decisão implica em diferentes formas de adoção dos instrumentos gerenciais. O uso desse teste decorre do fato dos testes KolmogorovSmirnov e Shapiro-Wilk terem indicado que os dados não apresentam distribuição normal (sig<0,05). O teste de Mann-Whitney U, conforme Fávero et al. (2009, p. 163), "é aplicado para testar se duas amostras independentes foram extraídas de populações com médias iguais. Ele é uma alternativa ao teste paramétrico $t$ para duas amostras independentes quando a amostra for pequena e/ou quando a hipótese de normalidade for violada".

\section{DESCRIÇÃO E ANÁLISE DOS DADOS}

\subsection{DADOS DEMOGRÁFICOS DAS EMPRESAS E RESPONDENTES}

Na Tabela 1, evidenciam-se dados demográficos acerca das empresas investigadas.

Tabela 1 - Perfil das empresas

\begin{tabular}{l|c|c|l|c|c}
\hline \multicolumn{1}{c|}{ Ramo de atividade } & Quantidade & $\mathbf{\%}$ & Regime de tributação & Quantidade & \% \\
\hline Comércio varejista & 12 & $29,27 \%$ & Simples Nacional & 37 & $90,24 \%$ \\
Comércio atacadista & 1 & $2,27 \%$ & Lucro Presumido & 0 & $0,00 \%$ \\
Indústria & 19 & $43,18 \%$ & Lucro Real & 4 & $9,76 \%$ \\
Serviços & 9 & $20,45 \%$ & Lucro Arbitrado & 0 & $0,00 \%$ \\
Outros & 0 & $0,00 \%$ & Não conheço & 0 & $0,00 \%$ \\
\hline Total & $\mathbf{4 1}$ & $\mathbf{1 0 0 \%}$ & Total & $\mathbf{4 1}$ & $\mathbf{1 0 0 \%}$ \\
\hline \multicolumn{1}{c}{$\mathbf{N}^{\mathbf{0}}$ de funcionários } & Quantidade & $\mathbf{\%}$ & Classificação do desempenho & Quantidade & $\mathbf{\%}$ \\
\hline Até 9 pessoas & 28 & $68,29 \%$ & Acima da média & 7 & $17,07 \%$ \\
De 10 a 49 pessoas & 8 & $19,51 \%$ & Na média & 29 & $70,73 \%$ \\
De 50 a 99 pessoas & 5 & $12,20 \%$ & Abaixo da média & 4 & $9,76 \%$ \\
Acima de 100 pessoas & 0 & $0,00 \%$ & Não sei informar & 1 & $2,44 \%$ \\
\hline Total & $\mathbf{4 1}$ & $\mathbf{1 0 0 \%}$ & Total & $\mathbf{4 1}$ & $\mathbf{1 0 0 \%}$ \\
\hline
\end{tabular}

Fonte: Dados da pesquisa.

Observa-se na Tabela 1, que a amostra compõe-se de 19 empresas $(43,18 \%)$ industriais, 12 empresas $(29,27 \%)$ do comércio varejista, nove empresas $(20,45 \%)$ de serviços e uma empresa $(2,27 \%)$ de comércio atacadista. Quanto ao regime de tributação, a maioria das empresas (37), correspondendo a 90,24\%, é tributada pelo regime do Simples Nacional, e 
apenas quatro empresas $(9,76 \%)$ são tributadas pelo Lucro Real. Destaca-se que 19 empresas têm faturamento inferior a R \$ 360.000,00, caracterizando-se como micro empresas; 19 têm faturamento bruto anual entre $\mathrm{R} \$ 360.000,01$ e $\mathrm{R} \$ 3.600 .000,00$, classificadas como empresas de pequeno porte; e três empresas possuem faturamento bruto anual superior a $\mathrm{R} \$$ 3.600.000,01, classificadas como empresas médias, conforme critérios da Receita Federal do Brasil.

Em relação ao número de funcionários, a maior parte das empresas possui até nove funcionários. Nenhuma empresa indicou ter mais de 100 funcionários. O número máximo de funcionários apontado pelas empresas foi de 95. A categoria do número de funcionários adotada é consubstanciada nos estudos de Silva et al. (2010), Anjos et al. (2012) e Moreira et al. (2013), que utilizaram os critérios propostos pelo SEBRAE. Na pesquisa realizada por Silva et al. (2010), 63,6\% das empresas possuíam até 9 funcionários, e de Anjos et al. (2012), $61,5 \%$ se enquadravam nesta categoria. Nesta pesquisa, $68,29 \%$ empresas foram classificadas nesta primeira faixa, o que indica que a maioria é classificada como microempresa.

No que concerne à longevidade das empresas, medida pelo tempo de constituição, grande parte atua no mercado no máximo há 20 anos. A maior concentração está na faixa de 2 a 5 anos, com 19 empresas (46,34\%); entre 11 e 20 anos há 10 empresas (24,39\%); entre 6 e 10 anos $(17,07 \%)$ há 7 empresas. Poucas empresas atuam há mais de 20 anos, totalizando quatro empresas $(9,76 \%)$. E uma empresa está há menos de um ano no mercado. Infere-se que uma parte considerável das empresas ainda não alcançou o estágio de maturidade, que ocorre quando passam dos cinco anos de sobrevivência.

Ao cotejar esta característica com estudos anteriores, observa-se em Moreira et al. (2013) que 51,4\% das empresas pesquisadas apresentaram 10 ou mais anos de existência, ao passo que 25,40\% possuíam até 3 anos de funcionamento. Enquanto que em Alves et al. (2013), um número mais expressivo $(55,1 \%)$ está relacionado com o tempo de existência das empresas com até 5 anos de vida. No estudo de Lima e Imoniana (2008), 41\% das empresas apresentaram mais de 20 anos de existência, o que diverge do presente estudo.

Questionou-se ainda sobre a classificação que os gestores atribuem ao desempenho quando comparado com os seus concorrentes. Dos respondentes, 29 (70,73\%) afirmaram que, comparado ao desempenho dos concorrentes, seu desempenho está "na média"; sete gestores $(17,07 \%)$ classificaram o desempenho de sua empresa como acima da média, enquanto que quatro gestores $(9,76 \%)$ classificaram o desempenho abaixo da média e um gestor $(2,44 \%)$ não soube informar. O resultado da pesquisa corrobora com o de Miranda et al. (2008), que observou que $78,8 \%$ das empresas veem seu desempenho na média quando comparado com seus concorrentes.

Investigou-se ainda o perfil dos gestores das empresas pesquisadas, em específico, o gênero, idade, grau de escolaridade, área de formação do respondente, além da função que ocupa na empresa e a frequência na qual realiza cursos de gestão. Constatou-se que não há predominância de um gênero na administração das empresas, pois o masculino representou $51,22 \%$ da amostra contra $48,78 \%$ do gênero feminino. A faixa etária predominante está entre os 41 e 50 anos, com 13 respondentes (31,71\%). A segunda faixa etária com maior predominância é de menos de 25 anos, com sete respondentes (17,07\%). Os demais resultados referentes ao perfil dos respondentes estão sintetizados na Tabela 2. 
Tabela 2 - Perfil dos Respondentes

\begin{tabular}{lcc|lcc}
\hline \multicolumn{1}{c}{ Escolaridade } & Quant. & $\mathbf{\%}$ & \multicolumn{1}{c}{ Área de formação } & Quant. & \% \\
\hline Ensino fundamental incompleto & 4 & $9,76 \%$ & Administração & 6 & $37,50 \%$ \\
Ensino fundamental completo & 2 & $4,88 \%$ & Ciências Contábeis & 6 & $37,50 \%$ \\
Ensino médio incompleto & 2 & $4,88 \%$ & Engenharia Civil & 1 & $5,88 \%$ \\
Ensino médio completo & 12 & $29,27 \%$ & Engenharia Florestal & 1 & $5,88 \%$ \\
Ensino superior incompleto & 9 & $21,95 \%$ & Pedagogia & 2 & $11,76 \%$ \\
Ensino superior completo & 12 & $29,27 \%$ & Técnico & 1 & $5,88 \%$ \\
Especialização & 6 & $14,63 \%$ & Total & $\mathbf{1 6}$ & $\mathbf{1 0 0 \%}$ \\
\hline Função que ocupa na empresa & Quant. & $\mathbf{\%}$ & Realização de cursos de & Quant. & $\mathbf{\%}$ \\
\hline Administrador (a) & 25 & $60,98 \%$ & Frequentemente & 6 & $14,63 \%$ \\
Diretor & 2 & $4,88 \%$ & Com pouca frequência & 19 & $46,34 \%$ \\
Financeiro & 1 & $2,44 \%$ & Raramente & 11 & $26,83 \%$ \\
Gestor de projetos & 1 & $2,44 \%$ & Nunca & 5 & $12,20 \%$ \\
RH & 2 & $4,88 \%$ & Outro & 0 & $0,00 \%$ \\
Sócio gerente & 10 & $24,39 \%$ & & $\mathbf{4 1}$ & $\mathbf{1 0 0 \%}$ \\
\hline Total & $\mathbf{4 1}$ & $\mathbf{1 0 0 \%}$ & Total &
\end{tabular}

Fonte: Dados da pesquisa.

Observa-se na Tabela 2, quanto à escolaridade existem dois grupos de gestores, um deles que não possui e/ou não frequenta ensino superior, totalizando 20 respondentes; outro que possui curso superior completo ou em curso, com 21 respondentes. Dos 41 respondentes, seis possuem curso de especialização. A maioria dos respondentes exerce a função de administrador ou sócio gerente.

Dos respondentes que apresentam curso superior completo ou em curso, 12 possuem formação na área de gestão (administração e contabilidade), e 29 não apresentam formação na área de negócios. Destaca-se ainda como relevante o fato de que apenas $14,63 \%$ da amostra realizam cursos de gestão com frequência.

\subsection{PROCEDIMENTOS UTILIZADOS NA TOMADA DE DECISÃO}

O objetivo desta seção é verificar quais procedimentos são adotados na tomada de decisão das micro, pequenas e médias empresas pesquisadas. Inicialmente procurou-se identificar o responsável pela administração da empresa, pelo controle do setor financeiro e pelo controle da produção, cujos resultados constam na Tabela 3.

Observa-se na Tabela 3 que, tanto a administração da empresa, quanto o controle do setor financeiro e da produção são desempenhados pelos proprietários/sócios das empresas, com frequências de $92,68 \%, 80,49 \%$ e $75,61 \%$, respectivamente. Em poucas empresas as funções administrativa e financeira são exercidas por pessoas contratadas, portanto, os proprietários gerenciam seus negócios, mesmo sem formação compatível e/ou realização de cursos de gestão. Esses resultados convergem com os de Santos, Alves e Barreto (2012) e Callado e Pinho (2014), que os principais cargos das estruturas organizacionais de micro e pequenas empresas tendem a ser ocupados por pessoas que não possuem preparo específico, sendo na maioria das vezes o proprietário ou um membro da família. 
Tabela 3 - Responsável pela administração, setor financeiro e controle da produção da empresa

\begin{tabular}{l|c|c}
\hline \multicolumn{1}{c|}{ Responsável pelo comando/administração da empresa } & Número de respondentes & $\mathbf{\%}$ \\
\hline Proprietário/sócio & 38 & $92,68 \%$ \\
Administrador contratado & 2 & $4,88 \%$ \\
Gerente & 1 & $2,44 \%$ \\
Outro & 0 & $0,00 \%$ \\
\hline Total & $\mathbf{4 1}$ & $\mathbf{1 0 0 \%}$ \\
\hline \multicolumn{1}{c|}{ Responsável pelo setor financeiro } & Número de respondentes & $\mathbf{\%}$ \\
\hline Proprietário/sócio & 13 & $80,49 \%$ \\
Administrador contratado & 7 & $2,44 \%$ \\
Gerente & 0 & $17,07 \%$ \\
Outro & $\mathbf{4 1}$ & $0,00 \%$ \\
\hline Total & Número de respondentes & $\mathbf{1 0 0 \%}$ \\
\hline \multicolumn{1}{c|}{ Responsável pelo controle da produção da empresa } & 31 & $75,61 \%$ \\
\hline Proprietário/sócio & 1 & $2,44 \%$ \\
Administrador contratado & 7 & $17,07 \%$ \\
Gerente & 1 & $2,44 \%$ \\
Não se aplica & 1 & $2,44 \%$ \\
Outro & $\mathbf{4 1}$ & $\mathbf{1 0 0 \%}$ \\
\hline Total & & \\
\hline
\end{tabular}

Fonte: Dados da pesquisa.

Outras informações acerca do processo decisório das empresas foram investigadas, conforme demonstrado na Tabela 4.

Observa-se na Tabela 4, que em relação aos recursos mais utilizados para a tomada de decisão, destaca-se a experiência do empresário, apontada por 29 respondentes (70,73\%). Este resultado converge com o de Faria, Azevedo e Oliveira (2012), que destacam que esta característica inibe a importância das informações contábeis no processo decisório. Todavia, as informações contábeis constituem-se no segundo recurso mais utilizado, apontado por nove respondentes $(21,95 \%)$.

Os resultados da pesquisa realizada por Moreira et al. (2013) evidenciaram que 64,4\% dos gestores confiam na própria experiência, considerando-a importante no momento de lidar com as situações adversas do cotidiano. A pesquisa de mercado também foi elencada no estudo por 32,4\% dos respondentes, o que mostra, conforme Moreira et al. (2013), que estes se preocupam em obter informações sobre o mercado e suas variações como estratégia para se posicionar melhor diante de seus concorrentes. Por fim, 22,6\% da amostra utilizam os relatórios contábeis, o que converge com a presente pesquisa.

Sobre a consulta no momento de tomada de decisões financeiras, a família destaca-se como fonte mais consultada pelos gestores, com 22 respondentes $(53,66 \%)$. Chama a atenção que nove gestores não consultam a ninguém, tomam decisões sozinhos. Leone (1999) comenta que os gestores de pequenas empresas têm a característica de serem centralizadores e basearem a tomada de decisão na experiência. O fato da família estar envolvida na tomada de decisão pode gerar conflitos de interesses entre família e empresa. Ekanem (2005) apresentou evidências de que os gestores de pequenas empresas tomam decisões com base em suas experiências passadas e/ou das experiências de outros dentro de sua rede de contatos. 
Tabela 4 - Procedimentos utilizados na tomada de decisão

\begin{tabular}{|c|c|c|c|c|c|}
\hline Recursos utilizados & Qtde. & $\%$ & Sistemas utilizados & Qtde. & $\%$ \\
\hline Experiência do empresário & 29 & 70,73 & Manual (papel) & 19 & 46,34 \\
\hline $\begin{array}{l}\text { Informações fornecidas pela } \\
\text { contabilidade }\end{array}$ & 9 & 21,95 & Planilha Excel & 18 & 43,90 \\
\hline Relatórios elaborados pelos gestores & 9 & 21,95 & Pacote multiusuário & 4 & 9,76 \\
\hline Intuição & 2 & 4,88 & ERP & 3 & 7,32 \\
\hline Outros & 0 & 0,00 & Nenhum & 5 & 12,20 \\
\hline $\begin{array}{l}\text { Pessoas ou órgãos que recorrem para } \\
\text { tomada de decisão }\end{array}$ & Qtde. & $\%$ & $\begin{array}{l}\text { Conhecimento do resultado } \\
\text { mensal da empresa }\end{array}$ & Qtde. & $\%$ \\
\hline Família & 22 & 53,66 & Sim & 39 & 95,12 \\
\hline Contador & 14 & 34,15 & Não & 2 & 4,88 \\
\hline Ninguém, tomo as decisões sozinho & 9 & 21,95 & $\begin{array}{l}\text { Frequência que discute o resultado } \\
\text { da empresa com o contador }\end{array}$ & Qtde. & $\%$ \\
\hline Gerente de banco & 7 & 17,07 & Frequentemente & 10 & 24,39 \\
\hline Administrador externo à empresa & 7 & 17,07 & Com pouca frequência & 10 & 24,39 \\
\hline Consultor & 4 & 9,76 & Raramente & 17 & 41,46 \\
\hline SEBRAE & 1 & 2,44 & Nunca & 4 & 9,76 \\
\hline $\begin{array}{l}\text { Informações contábeis contribuem } \\
\text { com os objetivos da empresa? }\end{array}$ & Qtde. & $\%$ & $\begin{array}{l}\text { Utilização da Contabilidade no } \\
\text { apoio à gestão }\end{array}$ & Qtde. & $\%$ \\
\hline Sim, nas decisões diárias & 6 & 14,63 & Sim & 17 & 41,46 \\
\hline Sim, nas decisões estratégicas & 6 & 14,63 & Não & 24 & 58,54 \\
\hline Sim, nas decisões de financiamento & 7 & 17,07 & $\begin{array}{l}\text { Motivo da não utilização da } \\
\text { contabilidade no apoio à gestão }\end{array}$ & Qtde. & $\%$ \\
\hline Sim, nas decisões de investimento & 5 & 12,20 & Desconhece as utilidades & 13 & 31,71 \\
\hline $\begin{array}{l}\text { Sim, no acompanhamento dos negócios } \\
\text { e atendimento da parte legal }\end{array}$ & 27 & 65,85 & $\begin{array}{l}\text { A informação contábil não reflete a } \\
\text { realidade da empresa }\end{array}$ & 13 & 31,71 \\
\hline \multirow[t]{2}{*}{ Não quero opinar } & 9 & 21,95 & $\begin{array}{l}\text { Falta de comunicação com o } \\
\text { contador }\end{array}$ & 5 & 12,20 \\
\hline & & & $\begin{array}{l}\text { Dificuldades para interpretar os } \\
\text { relatórios }\end{array}$ & 1 & 2,44 \\
\hline
\end{tabular}

Fonte: Dados da pesquisa.

Os sistemas utilizados, na maioria das empresas pesquisadas são manuais (46,34\%), seguidos de planilhas eletrônicas $(43,90 \%)$. Destaca-se aqui que cinco gestores $(12,20 \%)$ não utilizam nenhum sistema de apoio à tomada de decisão. Esses resultados estão em linha com os de Panucci Filho e Almeida (2011), que identificaram que a planilha Excel é o sistema mais utilizado. Segundo os autores, há uma tendência observacional de quanto menor a empresa e menos tempo de vida, maior o uso de sistemas manuais. Estes resultados também coadunam com o estudo realizado por Beuren, Barp e Filipin (2013) em 109 micro e pequenas empresas, que elas pouco utilizam sistemas de gestão integrados.

No tocante ao conhecimento do resultado mensal da empresa pelo gestor, a maioria $(95,12 \%)$ indicou conhecê-lo. Entretanto, estes gestores não procuram o contador para discutir tal resultado ou não o fazem de forma constante, visto que 17 gestores $(41,46 \%)$ raramente procuram o contador para discutir o resultado da empresa; 10 gestores $(24,39 \%)$ procuram o contador com pouca frequência e 10 gestores (24,39\%) responderam que discutem frequentemente o resultado da empresa com o contador.

Sobre a informação contábil contribuir com os objetivos da empresa, 27 gestores responderam que sim, porém apenas no acompanhamento dos negócios e no atendimento da 
parte legal. As informações contribuem nas decisões diárias e estratégicas foi indicado por seis gestores, que tais informações auxiliam nas decisões de financiamento foi apontado por sete gestores e cinco gestores indicaram que a contabilidade auxilia nas decisões de investimento. Serrasqueiro e Nunes (2004) também constataram que a contabilidade da empresa presta serviços básicos, como o atendimento à parte legal, o que indica que, possivelmente, a contabilidade da empresa é utilizada apenas para atendimento à legislação e não fornece informações que sustentam a tomada de decisão.

Investigou-se ainda a utilização da contabilidade como ferramenta de apoio à gestão. Os resultados apontaram que 24 empresas $(58,54 \%)$ não utilizam a contabilidade para este fim. Os principais motivos para a não utilização da contabilidade no apoio à gestão estão ligados à ideia de que a informação contábil não reflete a real situação da empresa e que os gestores não conhecem a utilidade da contabilidade (13 respondentes para cada, representando 54,17\%). Moraes e Escrivão Filho (2006, p. 131) mencionam que "quanto menor a empresa, menos estruturada em termos de níveis hierárquicos e menor a formalização de todos os processos, inclusive os relacionados aos fluxos de informação na empresa"

Os resultados desta pesquisa corroboram com os de Faria, Azevedo e Oliveira (2012), que os gestores desconhecem a utilidade da contabilidade. E que os gestores dificilmente irão conhecer a total utilidade da informação contábil, enquanto as prestadoras de serviços contábeis se voltarem somente aos serviços relacionados às obrigações de cunho fiscal. Os resultados também coadunam com Callado e Pinho (2014), que normalmente os sistemas de controle das micros e pequenas empresas são difusos e quase sempre centralizados, com decisões tomadas pelos proprietários sem a participação de importantes atores do processo.

\subsection{INSTRUMENTOS DA CONTABILIDADE GERENCIAL UTILIZADOS PELAS EMPRESAS INVESTIGADAS}

Nesta seção apresentam-se os instrumentos da contabilidade gerencial utilizados pelas empresas, segregados em controles operacionais, demonstrações contábeis, métodos de custeio e outros artefatos. Os respondentes foram solicitados a indicar entre três alternativas possíveis: (i) sim, utilizo na tomada de decisão, (ii) conheço, mas não utilizo na tomada de decisão e (iii) desconheço. Os resultados estão sintetizados na Tabela 5.

Observa-se na Tabela 5, entre as categorias de instrumentos da contabilidade gerencial analisadas, destaca-se o uso para os controles operacionais, predominando o uso do controle de contas a receber, controle de caixa e controle de custos e despesas, o que corrobora com Lima (2007), que estes controles são os mais utilizados nas micro e pequenas empresas. Mesmo com índice maior de adoção, tais resultados chamam atenção, pelo fato que alguns gestores não utilizam ou desconhecem tais instrumentos. $\mathrm{O}$ não uso e não conhecimento dos controles de contas a pagar foi apontado por 16 empresas, representando 39,03\%. O controle de estoque é adotado por apenas 20 empresas, embora do total da amostra 19 são industriais e 16 do ramo do comércio, o que requer conhecimento e controle das mercadorias. Este resultado não está em linha com a adoção do controle de custos e despesas, utilizado por 26 empresas. Como é possível controlar custos sem possuir controle de estoques? É possível que alguns gestores não tenham conhecimento suficiente sobre os conceitos de custos e despesas, o que pode resultar em decisões inadequadas, por exemplo, a formação do preço de venda.

Carvalho e Lima (2011) buscaram identificar as práticas gerenciais utilizadas pelas micro e pequenas empresas do setor de confecções da cidade de Sousa/PB. Os resultados evidenciaram que $97,8 \%$ das empresas possuem um controle de contas a pagar, 93,4\% indicaram ter controle de contas a receber e controle de caixa. Estes resultados foram bastante superiores aos encontrados no presente estudo. 
Tabela 5 - Instrumentos da Contabilidade Gerencial

\begin{tabular}{|c|c|c|c|c|c|c|c|c|}
\hline \multirow[t]{2}{*}{ Instrumentos } & \multicolumn{2}{|c|}{$\begin{array}{c}\text { Utilizado na } \\
\text { tomada de } \\
\text { decisão }\end{array}$} & \multicolumn{2}{|c|}{$\begin{array}{l}\text { Não utilizado na } \\
\text { tomada de } \\
\text { decisão }\end{array}$} & \multicolumn{2}{|c|}{$\begin{array}{c}\text { Desconhecido } \\
\text { pelo gestor }\end{array}$} & \multicolumn{2}{|c|}{ Total } \\
\hline & Quant. & $\%$ & Quant. & $\%$ & Quant. & $\%$ & Quant. & $\%$ \\
\hline $\begin{array}{l}\text { Controles operacionais } \\
\text { Controle de caixa } \\
\text { Controle de contas a pagar } \\
\text { Controle de contas a receber } \\
\text { Controle de estoques } \\
\text { Controle de custos e despesas }\end{array}$ & $\begin{array}{l}26 \\
25 \\
27 \\
20 \\
26\end{array}$ & $\begin{array}{l}63,41 \% \\
60,98 \% \\
65,85 \% \\
48,78 \% \\
63,41 \%\end{array}$ & $\begin{array}{c}8 \\
12 \\
8 \\
14 \\
11\end{array}$ & $\begin{array}{l}19,51 \% \\
29,27 \% \\
19,51 \% \\
34,15 \% \\
26,83 \%\end{array}$ & $\begin{array}{l}7 \\
4 \\
6 \\
7 \\
4\end{array}$ & $\begin{array}{c}17,07 \% \\
9,76 \% \\
14,63 \% \\
17,07 \% \\
9,76 \%\end{array}$ & 41 & $100 \%$ \\
\hline $\begin{array}{l}\text { Demonstrações contábeis } \\
\text { Balancete } \\
\text { Balanço Patrimonial e DRE } \\
\text { DVA } \\
\text { DFC } \\
\text { DMPL e DLPA } \\
\text { Notas explicativas }\end{array}$ & $\begin{array}{c}15 \\
16 \\
8 \\
13 \\
8 \\
10\end{array}$ & $\begin{array}{l}36,59 \% \\
39,02 \% \\
19,51 \% \\
31,71 \% \\
19,51 \% \\
24,39 \%\end{array}$ & $\begin{array}{l}17 \\
15 \\
17 \\
20 \\
18 \\
15\end{array}$ & $\begin{array}{l}41,46 \% \\
36,59 \% \\
41,46 \% \\
48,78 \% \\
43,90 \% \\
36,59 \%\end{array}$ & $\begin{array}{c}9 \\
10 \\
16 \\
8 \\
15 \\
16\end{array}$ & $\begin{array}{l}21,95 \% \\
24,39 \% \\
39,02 \% \\
19,51 \% \\
36,59 \% \\
39,02 \%\end{array}$ & 41 & $100 \%$ \\
\hline $\begin{array}{l}\text { Métodos de Custeio } \\
\text { Custeio por absorção } \\
\text { Custeio variável } \\
\text { Custeio padrão } \\
\text { Custeio ABC } \\
\text { Custo meta }\end{array}$ & $\begin{array}{l}8 \\
6 \\
5 \\
4 \\
9\end{array}$ & $\begin{array}{c}19,51 \% \\
14,63 \% \\
12,20 \% \\
9,76 \% \\
21,95 \%\end{array}$ & $\begin{array}{c}10 \\
11 \\
12 \\
10 \\
9\end{array}$ & $\begin{array}{l}24,39 \% \\
26,83 \% \\
29,27 \% \\
24,39 \% \\
21,95 \%\end{array}$ & $\begin{array}{l}23 \\
24 \\
24 \\
27 \\
23\end{array}$ & $\begin{array}{l}56,10 \% \\
58,54 \% \\
58,54 \% \\
65,85 \% \\
56,10 \% \\
\end{array}$ & 41 & $100 \%$ \\
\hline $\begin{array}{l}\text { Outros Artefatos } \\
\text { Retorno sobre investimento } \\
\text { Orçamento } \\
\text { Planejamento tributário } \\
\text { Ponto de equilíbrio } \\
\text { Planejamento estratégico }\end{array}$ & $\begin{array}{c}10 \\
9 \\
18 \\
12 \\
10\end{array}$ & $\begin{array}{l}24,39 \% \\
21,95 \% \\
43,90 \% \\
29,27 \% \\
24,39 \%\end{array}$ & $\begin{array}{c}15 \\
15 \\
8 \\
8 \\
13\end{array}$ & $\begin{array}{l}36,59 \% \\
36,59 \% \\
19,51 \% \\
19,51 \% \\
31,71 \%\end{array}$ & $\begin{array}{l}16 \\
17 \\
15 \\
21 \\
18\end{array}$ & $\begin{array}{l}39,02 \% \\
41,46 \% \\
36,59 \% \\
51,22 \% \\
43,90 \%\end{array}$ & 41 & $100 \%$ \\
\hline
\end{tabular}

Fonte: Dados da pesquisa.

Em relação às demonstrações contábeis, observa-se que nem a metade das empresas pesquisadas utiliza essas informações, talvez por não refletirem a realidade das empresas. $\mathrm{O}$ Balanço Patrimonial e a Demonstração do Resultado são utilizados por 16 empresas, ao passo que o menor índice de adoção recai sobre a DVA e DMPL ou DLPA. Isso pode ser atribuído ao fato da DVA somente ser exigida para sociedades anônimas de capital aberto. Oliveira, Muller e Nakamura (2000) alertam que as demonstrações contábeis são de difícil entendimento e estas empresas as concebem apenas para atendimento das exigências legais.

Estes resultados foram inferiores aos observados por Silva et al. (2010), que constataram que 36 empresas dentre 55 pesquisadas $(65,4 \%)$ utilizam a Demonstração do Resultado e o Balanço Patrimonial. Kos et al. (2011) observaram que a maioria dos gestores de micro e pequenas empresas não compreendem a informação contábil fornecida pelos contadores por não conhecer o significado de termos usados nesses relatórios, como por exemplo, lucro contábil, receita e despesa contábil e até mesmo Balanço Patrimonial.

Quanto aos métodos de custeio, qualquer um deles não contempla nem um quarto de adoção por estas empresas e mais de $50 \%$ não os conhecem e por isso não os utilizam. A adoção menor do custeio por atividades é compreensível, devido às características da amostra. No entanto, o não conhecimento e o consequente não uso do custeio variável evidencia fragilidades na gestão destas empresas, uma vez que a maioria é representada por empresas industriais e comerciais. A baixa utilização de métodos de custeio evidenciado na pesquisa 
converge com os resultados de Andrade et al. (2003) e Santos et al. (2014).

Por fim, em relação aos outros artefatos gerenciais, constata-se que sua utilização também não contempla nem $30 \%$ da amostra, com exceção do planejamento tributário, que é utilizado por 18 empresas $(43,90 \%)$. A maioria destas empresas não conhece ou não faz uso de artefatos importantes, por exemplo, do planejamento estratégico e do orçamento, que direcionam as estratégias e ações organizacionais. Resultados semelhantes foram observados por Andrade et al. (2003) e Panucci Filho e Almeida (2011). A pesquisa de Silva et al. (2010) indicou que a maioria dos gestores de micro e pequenas empresas não se utiliza da Contabilidade para acompanhar metas, medir desempenhos e avaliar impactos financeiros de suas decisões, deixando assim de fazer uso gerencial dos relatórios. Frezatti et al. (2012) aduzem que a não disponibilidade de artefatos em algumas organizações decorre da falta de uma discussão de infraestrutura que preceda à própria implementação do artefato.

Mcchlery, Godfrey e Meechan (2005) investigaram 416 pequenas empresas da Escócia, e constataram que os sistemas de controle orçamentário nestas empresas não são robustos, uma vez que muitas delas não elaboraram o orçamento, e das que o fazem, $61,35 \%$ não atualizam-no de forma regular. Além disso, 59,9\% das empresas fazem alguma forma de definição de metas de longo prazo e 36,8\% das empresas não utilizam nenhum sistema de custeio para os seus produtos ou serviços. Tais resultados, embora insatisfatórios, foram superiores aos apresentados na presente pesquisa, o que evidencia diferenças entre países no que concerne à adoção desses instrumentos gerenciais em pequenas empresas.

De modo geral, observa-se que os controles operacionais são utilizados na maioria das empresas pesquisadas. Quanto às demonstrações contábeis, não há utilização para a tomada de decisão, ao passo que os métodos de custeio são desconhecidos pelos gestores. Em relação aos outros instrumentos da contabilidade gerencial, há equilíbrio entre os gestores que os utilizam e os gestores que não os utilizam na tomada de decisão, mas a maioria afirma desconhecer tais artefatos da contabilidade gerencial.

\subsection{GRAU DE IMPORTÂNCIA DOS INSTRUMENTOS GERENCIAIS NA VISÃO DOS GESTORES}

Esta seção objetiva verificar o grau de importância atribuído aos instrumentos da contabilidade gerencial para a tomada de decisão nas empresas pesquisadas. Para cada um dos instrumentos gerenciais foi solicitado aos respondentes atribuir o seu grau de importância, considerando nada importante, pouco importante, indiferente, importante e muito importante. Os resultados foram analisados por meio da técnica da entropia da informação, com o intuito de analisar a variabilidade nas respostas dos gestores sobre a importância atribuída aos instrumentos gerenciais. Na Tabela 6, apresentam-se os instrumentos gerenciais e seus respectivos valores de entropia, peso da informação e média.

Constata-se na Tabela 6 que os controles de contas a pagar, contas a receber, custos e despesas, caixa, planejamento tributário e orçamento foram os que apresentaram maior grau de importância na visão dos gestores, cujas médias ficaram todas acima de 4, que na escala representa importante. Este resultado coaduna em parte com a utilização dos instrumentos pelos gestores, em que se constatou que os controles operacionais são os mais utilizados pelas empresas. Vale destacar que o orçamento é utilizado pela minoria, embora a maioria o considere importante. Por outro lado, a Demonstração de Valor Adicionado (DVA), o custeio meta, o custeio $\mathrm{ABC}$, o custeio variável e o custeio padrão destacaram-se negativamente com as menores médias, todas próximas a 3, que na escala utilizada corresponde a indiferente, ou seja, os respondentes não consideram estes instrumentos necessários à gestão do negócio. 
Tabela 6 - Grau de importância dos instrumentos na visão dos gestores

\begin{tabular}{c|l|c|c|c}
\hline $\mathbf{N}^{\mathbf{0}}$ & Questão & Entropia & Peso da Informação & Média \\
\hline 1 & Controle de contas a pagar & 0,9919 & 0,0264 & 4,49 \\
2 & Controle de contas a receber & 0,9901 & 0,0321 & 4,39 \\
3 & Controle de custos e despesas & 0,9908 & 0,0297 & 4,37 \\
4 & Caixa & 0,9841 & 0,0517 & 4,17 \\
5 & Planejamento tributário & 0,9914 & 0,0278 & 4,10 \\
6 & Orçamento & 0,9908 & 0,0298 & 4,05 \\
7 & Retorno sobre investimento & 0,9874 & 0,0408 & 4,00 \\
8 & Controle de estoques & 0,9799 & 0,0651 & 3,88 \\
9 & Planejamento estratégico & 0,9855 & 0,0469 & 3,80 \\
10 & DFC & 0,9874 & 0,0408 & 3,76 \\
11 & Cálculo do ponto de equilíbrio & 0,9834 & 0,0538 & 3,71 \\
12 & BP e DRE & 0,9809 & 0,062 & 3,68 \\
13 & Balancete & 0,9824 & 0,0571 & 3,68 \\
14 & DMPL e DLPA & 0,9863 & 0,0443 & 3,66 \\
15 & Notas explicativas & 0,9838 & 0,0525 & 3,59 \\
16 & DVA & 0,986 & 0,0455 & 3,44 \\
17 & Custeio meta & 0,9827 & 0,0562 & 3,27 \\
18 & Custeio ABC & 0,9839 & 0,0521 & 3,22 \\
19 & Custeio variável & 0,9798 & 0,0655 & 3,17 \\
20 & Custeio padrão & 0,9804 & 0,0636 & 3,15 \\
21 & Custeio por absorção & 0,9827 & 0,0561 & 3,15 \\
\hline Total & & $\mathbf{2 0 , 6 9 1 8}$ & $\mathbf{1 , 0 0}$ & $\mathbf{3 , 7 5}$ \\
\hline
\end{tabular}

Fonte: Dados da pesquisa.

Quanto à entropia da informação e ao peso, Zeleny (1982) explica que quanto maior for o e(di), menor é a informação transmitida e quanto mais próximo de zero for o e(di), maior o grau de entropia presente. Em relação ao peso, o autor explica que o peso $\lambda_{i}$ é inversamente relacionado ao e(di), assim, quanto maior, maior é a diversidade de opiniões entre os respondentes. Analisando o grupo de questões, os resultados evidenciam que os instrumentos com menor dispersão nas respostas foram o controle de contas a receber, o orçamento, o controle de custos e despesas, o planejamento tributário e o controle de contas a pagar, visto que estes instrumentos apresentaram maior entropia e menor peso de informação. Isso denota que há concordância entre os gestores sobre a importância destes instrumentos para a gestão de suas organizações.

Depreende-se que dos cinco instrumentos elencados com maior entropia, quatro deles (contas a receber, custos e despesas, planejamento tributário e contas a pagar) também apresentaram as melhores médias, indicando que há concordância de que estes são importantes à gestão das organizações.

No entanto, em alguns instrumentos não houve o mesmo grau de concordância entre os respondentes, fato este demonstrado pelo alto peso da informação. Neste sentido, destacase o custeio variável como o instrumento em que houve maior variabilidade entre as respostas, uma vez que apresentou o maior peso da informação $(0,0655)$. Tal variabilidade é evidenciada na Figura 1. 


\section{Figura 1 - Variabilidade das respostas - Custeio Variável e Estoques}

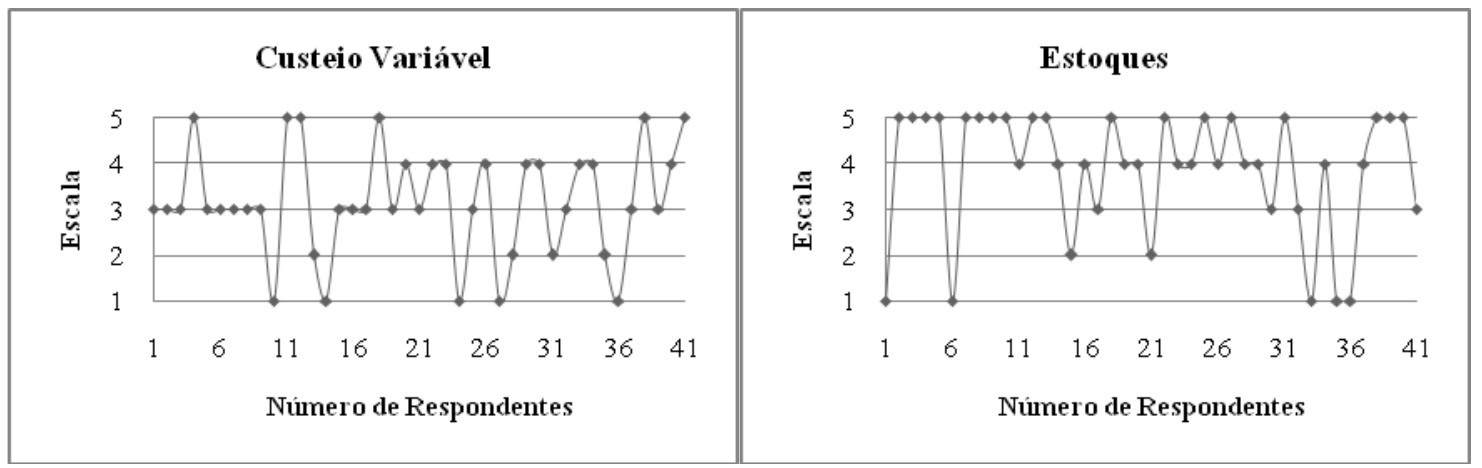

Fonte: Dados da pesquisa.

Observa-se na Figura 1, que não houve concordância entre os respondentes em relação ao grau de importância do custeio variável. Enquanto alguns respondentes consideram este instrumento muito importante, representado no gráfico pelo número 5, outros consideram-no nada importante, que corresponde ao número 1 do gráfico. A média de opinião em relação a este instrumento é a terceira mais baixa $(3,17)$ entre os instrumentos analisados.

Quanto a variabilidade das respostas para o instrumento controle de estoques, este instrumento apresentou o segundo maior peso da informação, o que demonstra pouca concordância entre os gestores acerca de sua importância à gestão da organização. $\mathrm{O}$ gráfico sobre controle de estoques denota que comparativamente ao número de gestores que consideram este instrumento nada importante, a quantidade que consideram-no muito importante é elevada. Isso pode explicar a média deste instrumento se apresentar muito próxima a quatro. No entanto, muitas respostas distribuíram-se entre os pontos intermediários da escala, o que contribuiu para o baixo grau de entropia da informação deste instrumento.

Outros instrumentos que apresentaram maior variabilidade nas respostas são o custeio padrão e o Balanço Patrimonial e DRE, conforme Figura 2.

\section{Figura 2 - Variabilidade das respostas - Custeio Padrão e Balanço Patrimonial / DRE}
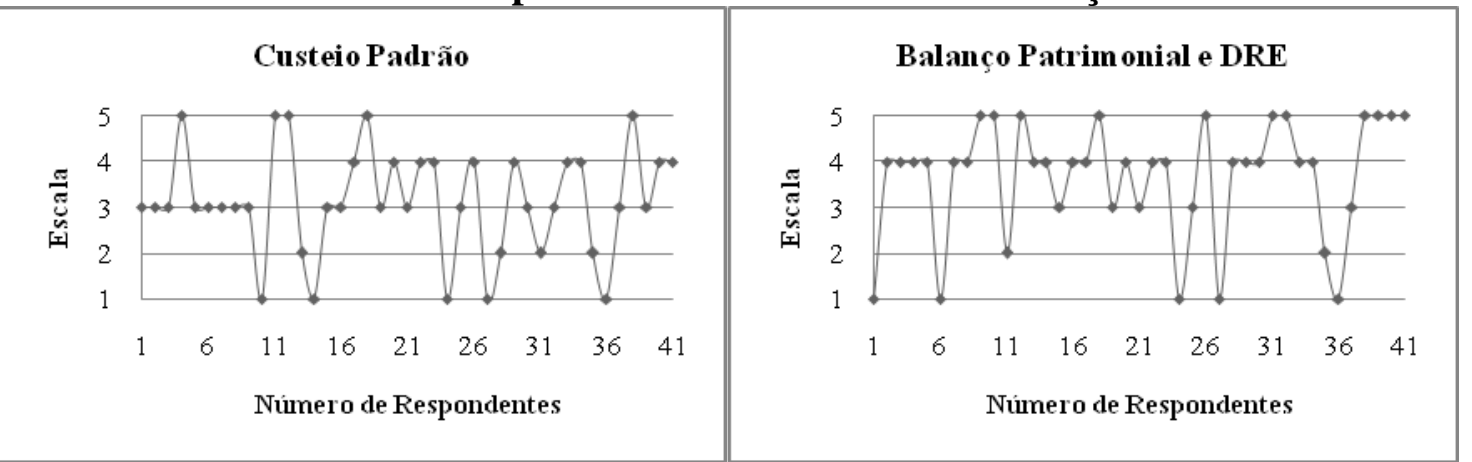

Fonte: Dados da pesquisa.

O custeio padrão apresentou o terceiro maior peso da informação $(0,0636)$, enquanto o Balanço Patrimonial e a DRE o quarto maior peso $(0,062)$, o que indica pouca concordância entre os respondentes acerca da importância destes instrumentos. Na Figura 2, observa-se a variabilidade entre as respostas dos gestores. Ressalta-se que o custeio padrão também apresentou uma das menores médias de importância $(3,18)$, mas, ao analisar o gráfico de dispersão das respostas, nota-se que a maior parte das respostas concentra-se nos pontos extremos da escala (muito importante ou nada importante). 


\subsection{UTILIZAÇ̃̃O DE INSTRUMENTOS GERENCIAIS VERSUS PROCEDIMENTOS NA TOMADA DE DECISÃO}

Nesta seção analisa-se se o uso de determinados procedimentos na tomada de decisão implica em diferentes formas de adoção dos instrumentos gerenciais. Para tanto, foi utilizado o teste não paramétrico Mann-Whitney U, sendo que, se o nível de significância for igual ou menor a 0,05 , indicará que há diferenças entre os grupos analisados. Analisaram-se grupos distintos no que concerne aos seguintes procedimentos de tomada de decisão:

a) recursos utilizados - comparou se os gestores que utilizam a experiência ou intuição diferem na utilização dos instrumentos gerenciais com os gestores que utilizam as informações fornecidas pela contabilidade e/ou de relatórios elaborados pelos gestores;

b) sistemas utilizados - a comparação foi realizada entre empresas que não utilizam nenhum sistema e/ou realizam controles manuais (papel) com empresas que usam planilha Excel, pacote multiusuário e/ou sistema ERP;

c) frequência com que os gestores discutem o resultado da empresa com o contador compararam-se empresas que raramente ou nunca discutem o resultado da empresa com o contador com aquelas em que a discussão do resultado acontece frequentemente e/ou com pouca frequência.

Outros testes foram realizados com o intuito de obter fatores explicativos acerca da utilização de instrumentos gerenciais, mas não foram encontradas evidências estatisticamente significativas que diferenciem a amostra. Neste escopo, enquadram-se os seguintes testes: a) ramo de atividade, segregando as empresas industriais das demais, sendo que somente o custeio por absorção e custeio variável apresentaram diferenças estatisticamente significantes; b) escolaridade, segregando os gestores sem curso superior daqueles que frequentam e/ou já o concluíram. Nenhum instrumento apresentou diferenças nas amostras, o que diverge dos estudos de Angelakis, Theriou e Floropoulos (2010) e Anjos et al. (2012). Também foram realizados testes separando gestores com formação em contabilidade e/ou administração daqueles sem formação específica ou formação em outras áreas. As diferenças encontradas foram significantes apenas para o Balanço Patrimonial e DRE, em que há maior utilização pelos gestores com conhecimentos da área.

$\mathrm{Na}$ Tabela 7, evidencia-se a comparação realizada entre os gestores (24) que se utilizam somente da intuição e/ou experiência com aqueles (17) que se utilizam de informações fornecidas pela contabilidade e/ou de relatórios elaborados pelos gestores.

Nas situações em que mais de um procedimento de tomada de decisão foi assinalado, considerou-se o que representa a melhor situação. Por exemplo, em relação aos recursos utilizados, caso algum gestor tenha indicado experiência e relatórios, foi considerado que a empresa utiliza os relatórios dos gestores e informações contábeis. Já os instrumentos gerenciais foram classificados em três categorias, assim enumeradas: $0=$ quando são desconhecidos pelos gestores; 1=não utilizados pelos gestores, porém conhecidos; e $2=$ utilizados pelos gestores, conforme já evidenciado na Tabela 5. Nesses não havia a possibilidade de mais uma alternativa. 
Tabela 7 - Comparação entre utilização de instrumentos gerenciais e recursos utilizados na tomada de decisão

\begin{tabular}{|c|c|c|c|c|c|}
\hline $\begin{array}{l}\text { Instrumentos Gerenciais } \\
\text { Controles operacionais }\end{array}$ & Recursos utilizados & $\mathbf{N}$ & Média dos Postos & Mann-Whitney U & Sig \\
\hline \multirow{2}{*}{ Controle de caixa } & Intuição/Experiência & 24 & 18,50 & \multirow{2}{*}{144,0} & \multirow{2}{*}{0,068} \\
\hline & Informação Contábil/Relatórios & 17 & 24,53 & & \\
\hline \multirow{2}{*}{$\begin{array}{c}\text { Controle de contas a } \\
\text { pagar }\end{array}$} & Intuição/Experiência & 24 & 17,65 & \multirow{2}{*}{123,5} & \multirow{2}{*}{$\mathbf{0 , 0 1 4}$} \\
\hline & Informação Contábil/Relatórios & 17 & 25,74 & & \\
\hline \multirow{2}{*}{$\begin{array}{c}\text { Controle de contas a } \\
\text { receber }\end{array}$} & Intuição/Experiência & 24 & 17,79 & \multirow{2}{*}{127,0} & \multirow{2}{*}{$\mathbf{0 , 0 1 5}$} \\
\hline & Informação Contábil/Relatórios & 17 & 25,53 & & \\
\hline \multirow{2}{*}{ Controle de estoques } & Intuição/Experiência & 24 & 17,98 & \multirow{2}{*}{131,5} & \multirow{2}{*}{$\mathbf{0 , 0 3 6}$} \\
\hline & Informação Contábil/Relatórios & 17 & 25,26 & & \\
\hline \multirow{2}{*}{$\begin{array}{c}\text { Controle de custos e } \\
\text { despesas }\end{array}$} & Intuição/Experiência & 24 & 17,23 & \multirow{2}{*}{113,5} & \multirow{2}{*}{0,005} \\
\hline & Informação Contábil/Relatórios & 17 & 26,32 & & \\
\hline \multicolumn{6}{|l|}{$\begin{array}{l}\text { Demonstrações } \\
\text { contábeis }\end{array}$} \\
\hline \multirow{2}{*}{ Balancete } & Intuição/Experiência & 24 & 19,42 & \multirow{2}{*}{166,0} & \multirow{2}{*}{0,281} \\
\hline & Informação Contábil/Relatórios & 17 & 23,24 & & \\
\hline \multirow{2}{*}{ BP e DRE } & Intuição/Experiência & 24 & 21,56 & \multirow{2}{*}{190,5} & \multirow{2}{*}{0,702} \\
\hline & Informação Contábil/Relatórios & 17 & 20,21 & & \\
\hline \multirow{2}{*}{ DVA } & Intuição/Experiência & 24 & 20,21 & 1850 & 0.588 \\
\hline & Informação Contábil/Relatórios & 17 & 22,12 & 105,0 & 0,500 \\
\hline $\mathrm{DFC}$ & Intuição/Experiência & 24 & 19,23 & 1615 & $022-3$ \\
\hline DFC & Informação Contábil/Relatórios & 17 & 23,50 & 101,3 & $0,2<1$ \\
\hline DMPI /DI PA & Intuição/Experiência & 24 & 22,40 & 1705 & 0330 \\
\hline DIVITL/DLF A & Informação Contábil/Relatórios & 17 & 19,03 & $1 / 0,3$ & 0,539 \\
\hline NES & Intuição/Experiência & 24 & 20,15 & 1835 & 0563 \\
\hline & Informação Contábil/Relatórios & 17 & 22,21 & & \\
\hline Métodos de Custeio & & & & & \\
\hline Custeio por absorcão & Intuição/Experiência & 24 & 19,69 & 1725 & 0352 \\
\hline Custero por adsorçao & Informação Contábil/Relatórios & 17 & 22,85 & $1 / 2,0$ & 0,352 \\
\hline Cucteis variável & Intuição/Experiência & 24 & 20,13 & 1830 & 0520 \\
\hline Custero valiaver & Informação Contábil/Relatórios & 17 & 22,24 & $10 J, 0$ & 0,523 \\
\hline Custeio nadrão & Intuição/Experiência & 24 & 20,31 & 1875 & 0619 \\
\hline & Informação Contábil/Relatórios & 17 & 21,97 & $18 /, 3$ & 0,019 \\
\hline Custeio $A B C$ & Intuição/Experiência & 24 & 21,81 & 1845 & 0537 \\
\hline & Informação Contábil/Relatórios & 17 & 19,85 & & \\
\hline Custo meta & Intuição/Experiência & 24 & 20,54 & 1930 & 0745 \\
\hline Casto inteta & Informação Contábil/Relatórios & 17 & 21,65 & 1) & $0, i+J$ \\
\hline Outros Artefatos & & & & & \\
\hline Retorno sobre & Intuição/Experiência & 24 & 19,50 & 1680 & 0309 \\
\hline investimento & Informação Contábil/Relatórios & 17 & 23,12 & & \\
\hline Orcamento & Intuição/Experiência & 24 & 19,50 & 168.0 & 0.307 \\
\hline & Informação Contábil/Relatórios & 17 & 23,12 & & \\
\hline Planeiamento tributário & Intuição/Experiência & 24 & 21,15 & 2005 & 0.920 \\
\hline Planejamento trioutario & Informação Contábil/Relatórios & 17 & 20,79 & 200,5 & 0,920 \\
\hline Ponto de equilíbrio & Intuição/Experiência & 24 & 18,71 & 1490 & 0111 \\
\hline Ponto de equintono & Informação Contábil/Relatórios & 17 & 24,24 & 149,0 & 0,111 \\
\hline Planejamento estratégico & Intuição/Experiência & 24 & 18,52 & 144,5 & 0.910 \\
\hline & Informação Contábil/Relatórios & 17 & 24,50 & & \\
\hline
\end{tabular}

Fonte: Dados da pesquisa. 
Observa-se na Tabela 7 , que quatro instrumentos gerenciais têm utilização significativamente diferente entre empresas cuja tomada de decisão ocorre de forma intuitiva e/ou com base na experiência do empresário comparativamente aquelas empresas que tomam decisões com base em informações fornecidas pela contabilidade e/ou relatórios gerados pelos gestores contratados. As empresas que consubstanciam suas decisões com informações contábeis e relatórios utilizam com maior intensidade os seguintes controles operacionais: controle de contas a pagar, controle de contas a receber, controle de estoques, controle de custos e despesas. As decisões advindas desses controles podem estar relacionadas com a concessão de crédito aos clientes, níveis de estoques, redução de despesas, apuração de custos, antecipação ou postergação de pagamentos, realização de investimentos específicos. De acordo com Stroeher e Freitas (2008, p. 3), "a contabilidade possibilita à empresa coletar, processar e relatar informação para uma variedade de decisões operacionais e administrativas".

Nos demais instrumentos gerenciais os resultados não foram estatisticamente relevantes, pois apresentaram valor de p superior ao nível de significância de 5\%. Porém, a utilização de outros artefatos gerenciais (retorno sobre investimento, orçamento, ponto de equilíbrio, planejamento estratégico), de métodos de custeio (absorção, variável, padrão, custo meta) e das demonstrações contábeis em geral é superior nas empresas cujas decisões são respaldadas com relatórios e informações contábeis. Este resultado indica que a forma como ocorre o processo decisório impacta na intensidade de utilização de instrumentos gerenciais.

Ao cotejar os resultados apresentados na Tabela $7 \mathrm{com}$ os que foram evidenciados na Tabela 5, verifica-se que na categoria demonstrações contábeis, o Balancete e a Demonstração dos Fluxos de Caixa são utilizados em maior intensidade nas empresas que tomam decisões baseadas em relatórios e informações contábeis. Uma das possíveis razões pela escolha do Balancete é que o mesmo engloba tanto as informações da DRE como do Balanço Patrimonial, e de forma mais analítica. Enquanto este relatório evidencia informações acerca do resultado da empresa, margens, grau de endividamento, relação de bens e obrigações, a DFC apresenta informações sobre caixa e equivalentes de caixa, o que conjuntamente gera informações tanto em nível financeiro, como patrimonial, operacional e econômico. Além disso, em relação às empresas que utilizam informações contábeis, o custeio por absorção e custeio variável são os métodos de custeio que aparecem com maior frequência, ainda que de forma tímida por muitas delas. O método de custeio por absorção é aceito pelo fisco e o custeio variável requer análises a partir da elaboração de relatórios.

Além disso, entre as empresas que se utilizam das informações contábeis e dos relatórios elaborados pelos gestores, a maior parte delas se constitui de indústrias, com faturamento anual médio de $\mathrm{R} \$ 2,4$ milhões, sendo o menor deles de $\mathrm{R} \$ 120$ mil e o maior de $\mathrm{R}$ \$ 15 milhões. A maioria refere-se a empresas de pequeno porte, conforme classificação da Receita Federal, o que sinaliza que o porte pode exercer influência na utilização dos instrumentos gerenciais. Ao analisar analiticamente, também se percebe que a maioria destas empresas conhecem o resultado mensal e o mesmo é discutido com o contador frequentemente ou com pouca frequência.

$\mathrm{Na}$ Tabela 8, apresentam-se os resultados das empresas cujos sistemas utilizados são a planilha Excel, pacote multiusuário e/ou sistema ERP com aquelas cujos controles são manuais ou ausentes. 
Tabela 8 - Comparação entre utilização de instrumentos gerenciais e sistemas utilizados na tomada de decisão

\begin{tabular}{|c|c|c|c|c|c|}
\hline $\begin{array}{l}\text { Instrumentos gerenciais } \\
\text { Controles operacionais }\end{array}$ & Sistemas utilizados & $\mathbf{N}$ & Média dos Postos & Mann-Whitney U & Sig \\
\hline \multirow{2}{*}{ Controle de caixa } & Nenhum/Manual (Papel) & 20 & 19,75 & \multirow{2}{*}{185,0} & \multirow{2}{*}{0,454} \\
\hline & Excel/ Pacote multiusuário/ERP & 21 & 22,19 & & \\
\hline \multirow{2}{*}{$\begin{array}{c}\text { Controle de contas a } \\
\text { pagar }\end{array}$} & Nenhum/Manual (Papel) & 20 & 20,80 & \multirow{2}{*}{206,0} & \multirow{2}{*}{0,904} \\
\hline & Excel/ Pacote multiusuário/ERP & 21 & 21,19 & & \\
\hline \multirow{2}{*}{$\begin{array}{c}\text { Controle de contas a } \\
\text { receber }\end{array}$} & Nenhum/Manual (Papel) & 20 & 19,95 & \multirow{2}{*}{189,0} & \multirow{2}{*}{0,514} \\
\hline & Excel/ Pacote multiusuário/ERP & 21 & 22,00 & & \\
\hline \multirow{2}{*}{ Controle de estoques } & Nenhum/Manual (Papel) & 20 & 18,68 & \multirow{2}{*}{163,5} & \multirow{2}{*}{0,186} \\
\hline & Excel/ Pacote multiusuário/ERP & 21 & 23,21 & & \\
\hline \multirow{2}{*}{$\begin{array}{c}\text { Controle de custos e } \\
\text { despesas }\end{array}$} & Nenhum/Manual (Papel) & 20 & 19,05 & \multirow{2}{*}{171,0} & \multirow{2}{*}{0,232} \\
\hline & Excel/ Pacote multiusuário/ERP & 21 & 22,86 & & \\
\hline \multicolumn{6}{|l|}{$\begin{array}{l}\text { Demonstrações } \\
\text { contábeis }\end{array}$} \\
\hline \multirow{2}{*}{ Balancete } & Nenhum/Manual (Papel) & 20 & 21,15 & \multirow{2}{*}{207,0} & \multirow{2}{*}{0,933} \\
\hline & Excel/ Pacote multiusuário/ERP & 21 & 20,86 & & \\
\hline \multirow{2}{*}{ BP e DRE } & Nenhum/Manual (Papel) & 20 & 20,15 & \multirow{2}{*}{193,0} & \multirow{2}{*}{0,635} \\
\hline & Excel/ Pacote multiusuário/ERP & 21 & 21,81 & & \\
\hline \multirow{2}{*}{ DVA } & Nenhum/Manual (Papel) & 20 & 22,15 & 1870 & 0518 \\
\hline & Excel/ Pacote multiusuário/ERP & 21 & 19,90 & 181,0 & 0,כ18 \\
\hline $\mathrm{DFC}$ & Nenhum/Manual (Papel) & 20 & 18,43 & 1585 & 0144 \\
\hline & Excel/ Pacote multiusuário/ERP & 21 & 23,45 & & \\
\hline DMPI /DI PA & Nenhum/Manual (Papel) & 20 & 19,03 & 1705 & 026 \\
\hline DIVIFL/DLFA & Excel/ Pacote multiusuário/ERP & 21 & 22,88 & $1 / 0,3$ & 0,200 \\
\hline NES & Nenhum/Manual (Papel) & 20 & 20,15 & 1930 & 0636 \\
\hline & Excel/ Pacote multiusuário/ERP & 21 & 21,81 & 193,0 & 0,050 \\
\hline Métodos de Custeio & & & & & \\
\hline Cucteio nor ahsorẽ̃o & Nenhum/Manual (Papel) & 20 & 18,30 & 156 & 01 \\
\hline Custelo por adsolçao & Excel/ Pacote multiusuário/ERP & 21 & 23,57 & 150,0 & 0,110 \\
\hline Custeio variável & Nenhum/Manual (Papel) & 20 & 16,85 & 1270 & 0014 \\
\hline Custelo variaver & Excel/ Pacote multiusuário/ERP & 21 & 24,95 & 121,0 & 0,014 \\
\hline Cucteio nadrõo & Nenhum/Manual (Papel) & 20 & 18,28 & 1555 & 0106 \\
\hline Custero paurao & Excel/ Pacote multiusuário/ERP & 21 & 23,60 & $1 J J, J$ & 0,100 \\
\hline Custein $\triangle \mathrm{BC}$ & Nenhum/Manual (Papel) & 20 & 19,90 & 1880 & 0493 \\
\hline 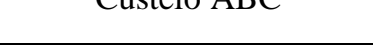 & Excel/ Pacote multiusuário/ERP & 21 & 22,05 & 100,0 & 0,43 \\
\hline Custo meta & Nenhum/Manual (Papel) & 20 & 19,40 & 1780 & 0352 \\
\hline & Excel/ Pacote multiusuário/ERP & 21 & 22,52 & & \\
\hline Outros Instrumentos & & & & & \\
\hline Retorno sobre & Nenhum/Manual (Papel) & 20 & 15,18 & 035 & 0001 \\
\hline investimento & Excel/ Pacote multiusuário/ERP & 21 & 26,55 & 95,3 & 0,001 \\
\hline Orcamento & Nenhum/Manual (Papel) & 20 & 17,20 & 1340 & 0.034 \\
\hline & Excel/ Pacote multiusuário/ERP & 21 & 24,62 & 134,0 & 0,034 \\
\hline Planeiamento tributário & Nenhum/Manual (Papel) & 20 & 18,88 & 1675 & 0232 \\
\hline & Excel/ Pacote multiusuário/ERP & 21 & 23,02 & & \\
\hline Ponto de equilíhrio & Nenhum/Manual (Papel) & 20 & 16,85 & 1270 & 0018 \\
\hline 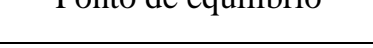 & Excel/ Pacote multiusuário/ERP & 21 & 24,95 & 121,0 & 0,010 \\
\hline Planeiamento estratéoico & Nenhum/Manual (Papel) & 20 & 16,65 & 1230 & $0.01+2>0$ \\
\hline & Excel/ Pacote multiusuário/ERP & 21 & 25,14 & 125,0 & \\
\hline
\end{tabular}

Fonte: Dados da pesquisa. 
Verifica-se na Tabela 8, que apenas o custeio variável, retorno sobre investimento, orçamento, ponto de equilíbrio e planejamento estratégico possuem médias estatisticamente diferentes entre empresas cujos controles ocorrem de forma manual comparativamente com aquelas que utilizam planilhas Excel, pacote multiusuário ou ERP. Tais instrumentos gerenciais contemplam, de modo geral, as etapas de planejamento, execução e controle. Entre os instrumentos analisados na categoria outros artefatos gerenciais, apenas o planejamento tributário não apresentou diferenças estatisticamente relevantes entre as amostras analisadas. Tal resultado já era esperado, uma vez que normalmente tal instrumento é oferecido pelas prestadoras de serviços contábeis, independente do sistema utilizado pelos seus clientes. Assim como as demonstrações contábeis.

Observa-se ainda que o uso e/ou conhecimento acerca dos controles operacionais e métodos de custeio, com exceção do custeio variável, não foram significativos, porém a adoção e/ou o conhecimento acerca destes instrumentos é maior naquelas empresas que fazem uso de planilhas ou sistemas ERP. Poucas empresas destacaram que fazem uso de métodos de custeio. Além disso, manualmente é possível realizar os controles operacionais elencados, mesmo que a forma possa ser considerada retrógrada e não eficiente.

Ao analisar de forma mais analítica as características destas empresas (que utilizam-se de planilhas e/ou sistemas), percebe-se que dentre as 21 , em 14 delas os gestores possuem curso superior em andamento ou concluído, sendo que oito possuem formação na área de administração e/ou Ciências Contábeis. Além disso, 15 gestores mencionaram que realizam cursos de gestão com frequência ou com pouca frequência. Tais resultados podem sinalizar que a busca por aprimoramento profissional, seja em nível de curso superior ou cursos relacionados à gestão, decorrem de maior grau de informatização das operações e, consequentemente, das informações geradas.

Observa-se ainda nas Tabelas 8 e 5, um número reduzido de empresas que adotam sistemas de informações para o gerenciamento das suas operações. Silva (2002) já havia constatado o baixo nível de informatização das empresas desse porte. $\mathrm{O}$ autor constatou que normalmente estas empresas investem muito mais em hardware do que em software. E que dificilmente estas empresas possuem sistema integrado de gestão. Isso dificulta o fornecimento de informações que possam auxiliar a administração da empresa e minimizar o risco na tomada de decisões estratégicas em relação ao mercado em que atuam.

Conforme Shahabi, Hosseinpour e Soheila (2014), a literatura evidencia que um sistema de contabilidade é um dos instrumentos de tomada de decisão mais eficazes de gestão. Ela fornece um método ordenado de reunir e organizar informações sobre as diversas transações comerciais de modo que possa ser aplicada como auxílio aos gestores na condução dos negócios empresariais. Na Tabela 9, demonstra-se se há diferenças entre o uso e/ou conhecimento dos instrumentos gerenciais por parte dos gestores que raramente ou nunca discutem o resultado da empresa com o contador com aqueles em que a discussão ocorre frequentemente ou com pouca frequência. 
Tabela 9 - Comparação entre utilização de instrumentos gerenciais e frequência que o resultado da empresa é discutido com o contador

\begin{tabular}{|c|c|c|c|c|c|}
\hline Instrumentos gerenciais & \multirow{2}{*}{$\begin{array}{l}\text { Frequência que o resultado da } \\
\text { empresa é discutido com o } \\
\text { contador }\end{array}$} & \multirow{2}{*}{$\mathbf{N}$} & \multirow{2}{*}{$\begin{array}{l}\text { Média dos } \\
\text { Postos }\end{array}$} & \multirow{2}{*}{$\begin{array}{c}\text { Mann- } \\
\text { Whitney U }\end{array}$} & \multirow{2}{*}{ Sig } \\
\hline Controles operacionais & & & & & \\
\hline \multirow{2}{*}{ Controle de caixa } & Raramente/Nunca & 21 & 16,62 & \multirow{2}{*}{118,0} & \multirow{2}{*}{0,006} \\
\hline & Com pouca frequência/Frequentemente & 20 & 25,60 & & \\
\hline \multirow{2}{*}{$\begin{array}{c}\text { Controle de contas a } \\
\text { pagar }\end{array}$} & Raramente/Nunca & 21 & 16,02 & \multirow{2}{*}{105,5} & \multirow{2}{*}{$\mathbf{0 , 0 0 2}$} \\
\hline & Com pouca frequência/Frequentemente & 20 & 26,23 & & \\
\hline \multirow{2}{*}{$\begin{array}{c}\text { Controle de contas a } \\
\text { receber }\end{array}$} & Raramente/Nunca & 21 & 17,17 & \multirow{2}{*}{129,5} & \multirow{2}{*}{$\mathbf{0 , 0 1 2}$} \\
\hline & Com pouca frequência/Frequentemente & 20 & 25,03 & & \\
\hline \multirow{2}{*}{ Controle de estoques } & Raramente/Nunca & 21 & 17,36 & \multirow{2}{*}{133,5} & \multirow{2}{*}{0,029} \\
\hline & Com pouca frequência/Frequentemente & 20 & 24,83 & & \\
\hline \multirow{2}{*}{$\begin{array}{c}\text { Controle de custos e } \\
\text { despesas }\end{array}$} & Raramente/Nunca & 21 & 17,38 & \multirow{2}{*}{134,0} & \multirow{2}{*}{$\mathbf{0 , 0 2 0}$} \\
\hline & Com pouca frequência/Frequentemente & 20 & 24,80 & & \\
\hline \multicolumn{6}{|l|}{$\begin{array}{l}\text { Demonstrações } \\
\text { contábeis }\end{array}$} \\
\hline \multirow{2}{*}{ Balancete } & Raramente/Nunca & 21 & 16,10 & \multirow{2}{*}{107,0} & 0004 \\
\hline & Com pouca frequência/Frequentemente & 20 & 26,15 & & 0,004 \\
\hline RP $\rho$ DRF & Raramente/Nunca & 21 & 20,45 & 1085 & 0748 \\
\hline DI C DTE & Com pouca frequência/Frequentemente & 20 & 21,58 & 190,5 & 0,148 \\
\hline DVA & Raramente/Nunca & 21 & 19,52 & 1700 & 0284 \\
\hline DVA & Com pouca frequência/Frequentemente & 20 & 22,55 & $1 / 9,0$ & 0,504 \\
\hline $\mathrm{DFC}$ & Raramente/Nunca & 21 & 17,76 & 1420 & 0054 \\
\hline DIC & Com pouca frequência/Frequentemente & 20 & 24,40 & 142,0 & 0,004 \\
\hline DMPL/DIPA & Raramente/Nunca & 21 & 20,69 & 2025 & 0055 \\
\hline & Com pouca frequência/Frequentemente & 20 & 21,33 & 203,3 & 0,85 \\
\hline NFS & Raramente/Nunca & 21 & 21,81 & 1030 & 0636 \\
\hline NES & Com pouca frequência/Frequentemente & 20 & 20,15 & 190,0 & 0,050 \\
\hline Métodos de Custeio & & & & & \\
\hline Custein nor ahsorcão & Raramente/Nunca & 21 & 21,14 & 2070 & 0030 \\
\hline Custerio poi ausurçau & Com pouca frequência/Frequentemente & 20 & 20,85 & 201,0 & 0, \\
\hline Cucteio varí́yel & Raramente/Nunca & 21 & 21,64 & 1065 & 0600 \\
\hline Custelo valiavel & Com pouca frequência/Frequentemente & 20 & 20,33 & $190, J$ & 0,090 \\
\hline Cucteio nadrão & Raramente/Nunca & 21 & 21,43 & 2010 & 0780 \\
\hline Custero paurao & Com pouca frequência/Frequentemente & 20 & 20,55 & 201,0 & 0,109 \\
\hline Cucteis $\triangle \mathrm{PC}$ & Raramente/Nunca & 21 & 21,17 & 2065 & 0012 \\
\hline Custelo ADC & Com pouca frequência/Frequentemente & 20 & 20,83 & 200,3 & 0,913 \\
\hline Gusto meta & Raramente/Nunca & 21 & 22,19 & 1850 & 0467 \\
\hline Custo imeta & Com pouca frequência/Frequentemente & 20 & 19,75 & $10 J, 0$ & 0,401 \\
\hline Outros Artefatos & & & & & \\
\hline Retorno sobre & Raramente/Nunca & 21 & 19,00 & 1680 & 0242 \\
\hline investimento & Com pouca frequência/Frequentemente & 20 & 23,10 & 168,0 & 0,242 \\
\hline Orcomentr $>$ & Raramente/Nunca & 21 & 19,67 & 1820 & 0424 \\
\hline Uiçamlento & Com pouca frequência/Frequentemente & 20 & 22,40 & 102,0 & 0,454 \\
\hline Planeiamento tributário & Raramente/Nunca & 21 & 21,79 & 1035 & 0643 \\
\hline 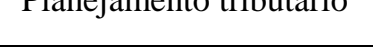 & Com pouca frequência/Frequentemente & 20 & 20,18 & & \\
\hline Ponto de equilíhrio & Raramente/Nunca & 21 & 18,17 & 1505 & 0080 \\
\hline romto de equintorio & Com pouca frequência/Frequentemente & 20 & 23,98 & 150,5 & 0,089 \\
\hline Planeiamente estratégico & Raramente/Nunca & 21 & 20,55 & 2005 & 0700 \\
\hline Planejamento estrategico & Com pouca frequência/Frequentemente & 20 & 21,48 & 200,5 & $0, / 90$ \\
\hline
\end{tabular}

Fonte: Dados da pesquisa. 
Nota-se na Tabela 9, que alguns instrumentos gerenciais apresentaram diferenças de utilização ou conhecimento estatisticamente significativas entre os dois grupos de empresas analisadas. As empresas que discutem com frequência o resultado com o contador apresentaram maior utilização acerca de todos os controles operacionais e do Balancete de Verificação. Estes resultados sugerem que o contador faz uso do Balancete para expor as informações contábeis, visto que se trata de uma demonstração mais analítica. Embora os controles operacionais não sejam normalmente oferecidos pelas prestadoras de serviços contábeis, a mesma pode orientar seus clientes a respeito da sua utilização, bem como esclarecer eventuais dúvidas.

Observa-se ainda, que nas empresas em que a discussão ocorre, há maior uso do retorno sobre investimento, orçamento, ponto de equilíbrio, planejamento estratégico, mesmo que tais diferenças não tenham sido estatisticamente significativas. Tais resultados evidenciam que reuniões entre gestores de pequenas empresas e contadores, podem levar a uma maior utilização de artefatos gerenciais ou conhecimento por parte do empresário. Ou seja, mesmo que as prestadoras de serviços contábeis não ofereçam o orçamento, a mesma pode indicar e explicar este instrumento aos empresários de pequenas empresas.

Bennett e Robson (1999) constataram que, embora a maioria das pequenas empresas da Grã-Bretanha utilizam fontes diferentes de conselhos, profissionais especializados é a fonte de assessoria externa mais frequentemente utilizada pelas mesmas. Além disso, constataram que os contadores são, juntamente com os clientes, classificados como as fontes externas de conselhos que têm maior impacto. Neste sentido, Marriot e Marriot (2000) concluíram que os contadores têm um importante papel a desempenhar no aumento da consciência financeira dos gestores das pequenas empresas e podem fornecer um serviço de contabilidade gerencial para atender suas necessidades e capacidades. Segundo Oyadomari et al. (2008), no Brasil as empresas de consultoria são aliadas dos administradores na legitimação das decisões tomadas pela organização. Oyadomari et al. (2011, p. 66) asseveram que "as empresas buscam esses profissionais de forma a legitimar o processo de introdução de um novo artefato".

Não foram constatadas diferenças entre os métodos de custeio, tal fato pode ser atribuído à duas possíveis razões: (i) baixa utilização deste instrumento por parte dos empresários, conforme indicado na Tabela 5; e (ii) prestadoras de serviços contábeis não estão orientando nesta área. Pelo fato da amostra se tratar de empresas enquadradas no sistema tributário do Simples Nacional, fiscalmente a mesma deve informar o valor do inventário apenas no encerramento do exercício, a partir da contagem física dos estoques. Assim, muitas vezes, proprietários de empresas com este enquadramento não possuem conhecimento acerca do custeio variável, custeio por absorção, custeio meta, entre outros.

A partir dos resultados apresentados, evidencia-se uma tendência de maior conhecimento e utilização de instrumentos gerenciais em micro e pequenas empresas com decisões respaldadas em relatórios e informações contábeis, que controlam suas operações por meio de sistemas, desde os mais simples, como planilhas Excel até sistemas ERP e cujos empresários discutem os resultados da empresa com o contador. A informatização implica em instrumentos cuja finalidade vai além da determinação do custo e controle financeiro, contemplando aspectos de redução de perdas de recursos, controle e planejamento gerencial. No entanto, tendo em conta a taxa de respostas relativamente pequena, os resultados deste estudo só devem ser tratados como indicativos. Estudos adicionais, com outras amostras de micro e pequenas empresas são necessários para confirmar estes resultados. 


\section{CONCLUSÕES}

O estudo investigou os instrumentos e procedimentos gerenciais utilizados na tomada de decisão de micro e pequenas empresas localizadas na região do Alto Vale do Itajaí, SC, Brasil. Os resultados da pesquisa evidenciam que a tomada de decisão é centralizada no proprietário destas empresas, que se utiliza da experiência pessoal e consulta a família para tomar decisões, sendo que o contador não é procurado para discussões sobre o resultado da organização. Em relação aos instrumentos gerenciais, observou-se que a maioria utiliza-se de controles operacionais, ao passo que as demonstrações contábeis não são utilizadas e os principais métodos de custeio são desconhecidos. Além disso, artefatos como planejamento estratégico, orçamento, retorno sobre investimento, ponto de equilíbrio, são desconhecidos ou não utilizados pelos gestores, embora reconheçam a sua importância.

Estes resultados coadunam em grande parte com os de pesquisas anteriores que relacionaram o processo de gestão das micro, pequenas e médias empresas com a utilização de instrumentos gerenciais. Os resultados da pesquisa apresentam uma visão simplista e equivocada dos gestores de que a contabilidade serve apenas para atender às exigências legais, fiscais e trabalhistas. A pesquisa levanta questões importantes, por exemplo, como é possível empresas industriais e comerciais não considerar importante o controle de estoques? Além disso, desconhecer e considerar sem relevância os métodos de custeio disponíveis? A situação se agrava ao constatar que algumas empresas não utilizam controles básicos, porém importantes, por exemplo, controles de caixa, controles de contas a pagar, controles de contas a receber.

Os resultados deste estudo merecem algumas reflexões por parte dos profissionais contábeis, entidades de classe e associações empresariais. Recomenda-se maior atenção à assessoria nestas organizações. As entidades empresariais, conselhos de classe, assim como, programas de extensão universitária da área de negócios poderiam ministrar cursos sobre algumas práticas gerenciais básicas, mas importantes, visando melhorar o controle patrimonial destas entidades. As prestadoras de serviços contábeis necessitam de mudanças de comportamento, visando maior aproximação com estes empresários, para que possam demonstrar a utilidade da informação contábil.

No entanto, algumas limitações da pesquisa podem ter influenciado nos resultados do estudo, como a pequena amostra analisada. O estudo utilizou-se do questionário como fonte de coleta de dados, baseado na percepção dos gestores destas empresas, assim aspectos subjetivos e possíveis vieses podem estar presentes e com implicações nas respostas, talvez distintas da realidade. Assim, recomenda-se ampliar a população da pesquisa, para compreender melhor as práticas gerenciais adotadas pelas micro e pequenas empresas.

Recomenda-se que estudos futuros alcancem as médias empresas, para comparar o comportamento das suas práticas gerenciais. Como esta pesquisa se restringiu aos instrumentos gerenciais utilizados na tomada de decisão das micro e pequenas empresas, recomenda-se ainda que estudos futuros busquem nas prestadoras de serviços contábeis os motivos da não disponibilização dos instrumentos gerenciais. Também considera-se pertinente a realização de entrevistas com gestores de pequenas empresas para averiguar a compreensão destes empresários acerca da contabilidade e seus instrumentos gerenciais.

\section{REFERÊNCIAS}

ABDEL-KADER, M.G.; LUTHER, R.G. IFAC's conception of the evolution of management accounting. In: EPSTEIN, M.J.; LEE, J.Y. (eds.) Advances in management accounting. UK: Emerald Group Publishing, 2006. Vol. 15. pp. 229-247.

ALVES, J.N.; SILVA, T.B.; TAVARES, C.E.M.; DAL-SOLTO, F. A utilização do 
planejamento estratégico como ferramenta de gestão na pequena empresa. Revista da Micro e Pequena Empresa, v. 7, n. 2, p. 80-100, 2013.

ANGELAKIS, G.; THERIOU, N.; FLOROPOULOS, I. Adoption and benefits of management accounting practices: evidence from Greece and Finland. Advances in Accounting, v. 26, n. 1, p. 87-96, 2010.

ANJOS, L.C.M; MIRANDA, L.C.; SILVA, D.J.C.; FREITAS, A.R.F. Uso da contabilidade para obtenção de financiamento pelas micro e pequenas empresas: um estudo a partir da percepção dos gestores. Revista Universo Contábil, v. 8, n. 1, p. 86-104, 2012.

ATKINSON, A.A; BANKER, R.D.; KAPLAN, R.S.; YOUNG, S.. Contabilidade gerencial. 2. ed. São Paulo: Atlas, 2008.

BENNETT, R.J.; ROBSON, P.J.A. The use of external business advice by SMEs in Britain. Entrepreneurship \& Regional Development, v. 11, n. 2, p. 155-180, 1999.

BERNARDES, D.P.G.; MIRANDA, L.C. Quatro histórias da utilização de informação econômico-financeira nas micro e pequenas empresas: lições para futuros empreendedores. Revista da Micro e Pequenas Empresas, v. 5, n. 3, p. 84-98, 2011.

BEUREN, I.M.; BARP, A.D.; FILIPIN, R. Barreiras e possibilidades de aplicação da contabilidade gerencial em micro e pequenas empresas por meio de empresas de serviços contábeis. ConTexto, v. 13, n. 24, p. 79-92, 2013.

CALLADO, A.A.C.; PINHO, M.A.B. Evidências de isomorfismo mimético sobre práticas de gestão de custos entre micro e pequenas empresas de diferentes setores de atividade. Contabilidade Vista \& Revista, v. 25, n. 2, p. 119-137, 2014.

CANECA, R.L.; MIRANDA, L.C.; RODRIGUES, R.N; LIBONATI, J.J.; FREIRE, D.R. A influência da oferta de contabilidade gerencial na percepção da qualidade dos serviços contábeis prestados aos gestores de micro, pequenas e médias empresas. Pensar contábil, v. 11, n. 3, p. 35-44, 2009.

CARVALHO, J. R. M.; LIMA, M. D. Práticas gerenciais em MPE'S do comércio de confecções da cidade de Souza/PB. Revista de Educação e Pesquisa em Contabilidade (REPEC), v. 5, n. 3, p. 39-65, 2011.

CHENHALL, R. H.; LANGFIELD-SMITH, K. The relationship between strategic priorities, management techniques and management accounting: an empirical investigation using a systems approach. Accounting, Organizations and Society, v. 23, n. 3, p. 243-264, 1998.

CORREIA, R.B. Ciclo de vida organizacional e instrumento de gestão: uma investigação nas empresas baianas. 2010. Dissertação (Mestrado em Ciências Contábeis) - Universidade Federal da Bahia, Salvador, 2010.

EKANEM, I. 'Bootstrapping': the investment decision-making process in small firms. The British Accounting Review, v. 37, n. 3, p. 299-318, 2005.

FARIA, J.A.; AZEVEDO, T.C.; OLIVEIRA, M.S. A utilização da contabilidade como ferramenta de apoio à gestão nas micro e pequenas empresas do ramo de comércio de material de construção de Feira de Santana/BA. Revista da Micro e Pequena Empresa, v. 6, n. 2, p. 89-106, 2012.

FREZATTI, F.; JUNQUEIRA, E.; BIDO, D.S.; NASCIMENTO, A.R.; RELVAS, T.R.S. Antecedentes da definição do design do sistema de controle gerencial: evidências empíricas nas empresas brasileiras. Brazilian Business Review, v. 9, n. 1, p. 134-155, 2012.

FREZATTI, F. Agrupamentos dos perfis da contabilidade gerencial no Brasil. Contabilidade, 
Gestão e Governança, v. 8, n. 1, p. 9-39, 2005.

GUERREIRO, R.; CORNACCHIONE JR, E.B.; SOUTES, D.O. Empresas que se destacam pela qualidade das informações a seus usuários externos também se destacam pela utilização de artefatos modernos de contabilidade gerencial. Revista Contabilidade \& Finanças, v. 22, n. 55, p. 88-113, 2011.

HORNGREN, C.T.; SUNDEM, G.L; STRATTON, W.O. Contabilidade gerencial. 12. ed. São Paulo: Prentice Hall, 2004.

IUDÍCIBUS, S. Contabilidade gerencial. 6. ed. São Paulo: Atlas, 1998.

KASSAI, S. As empresas de pequeno porte e a contabilidade. Caderno de Estudos, FIPECAFI, v. 9, n. 15, p. 60-74, 1997.

KOS, S. R.; ANJOS, R.P.; ESPEJO, M.M.S.B.; RAIFUR, L. Compreensão e utilização da informação contábil pelos micro e pequenos empreendedores em seus processos de gestão. In: CONGRESSO USP DE CONTROLADORIA E CONTABILIDADE, 11., 2011, São Paulo. Anais... São Paulo, 2011. CD-ROM.

LACERDA, J.B. A contabilidade como ferramenta gerencial na gestão financeira das micros, pequenas e médias empresas (MPMEs): necessidade e aplicabilidade. Revista Brasileira de Contabilidade, n. 160, p.39-53, 2006.

LEONE, N.M.C.P.G. As especificidades das pequenas e médias empresas. Revista de Administração da Universidade de São Paulo, v. 34, n. 2, 1999.

LIMA, A.N. Um estudo sobre a importância do uso das ferramentas de controle gerencial nas micro, pequenas e médias empresas industriais no município de São Caetano do Sul. 2007. 117f. Dissertação (Mestrado em Administração) - Universidade Metodista de São Paulo, São Bernardo do Campo, 2007.

LIMA, A.N.; IMONIANA, J.O. Um estudo sobre a importância do uso das ferramentas de controle gerencial nas micro, pequenas e médias empresas industriais no município de São Caetano do Sul. Revista da Micro e Pequena Empresa, v. 2, n. 3, p.28-48, 2008.

LOHR, M. Specificities of managerial accounting at SMEs: case studies from the German industrial sector. Journal of Small Business \& Entrepreneurship, v. 25, n. 1, p. 35-55, 2012.

MARRIOTT, N.; MARRIOTT, P. Professional accountants and the development of a management accounting service for the small firm: barriers and possibilities. Management Accounting Research, v. 11, n. 4, p. 475-492, 2000.

MCCHLERY, S.; GODFREY, A.D.; MEECHAN, L. Barriers and catalysts to sound financial management systems in small sized enterprises. Journal of Applied Accounting Research, v. 7, n. 3, p. 1-26, 2005.

MIRANDA, L.C.; LIBONATI, J.J.; FREIRE, D.R.; SATURNINO, O. Demanda por serviços contábeis pelos mercadinhos: são os contadores necessários? Contabilidade Vista \& Revista, v. 19, n. 1, p. 131-151, 2008.

MORAES, G.D.A.; ESCRIVÃO FILHO, E. A gestão da informação diante das especificidades das pequenas empresas. Ci. Inf, v. 35, n. 3, p. 124-132, 2006.

MOREIRA, R.L.; ENCARNAÇÃO, L.V.; BISPO, O.N.A.; ANGOTTI, M.; COLAUTO, R.D. A importância da informação contábil no processo de tomada de decisão nas micro e pequenas empresas. Revista Contemporânea de Contabilidade, v. 10, n.19, p. 119-140, 2013. 
Revista Ambiente Contábil - ISSN 2176-9036 - UFRN - Natal-RN. v. 8. n. 1, p. 153 - 186, jan./jun. 2016

OLIVEIRA, A.G.; MULLER, A.N.; NAKAMURA, W.T. A utilização das informações geradas pelo sistema de informação contábil como subsídio aos processos administrativos nas pequenas empresas. Revista FAE, v. 3. n. 3. p, 1-12, 2000.

OYADOMARI, J.C.T.; FREZATTI, F.; MENDONÇA NETO, O.R.; CARDOSO, R.L.; BIDO, D.S. Uso do sistema de controle gerencial e desempenho: um estudo em empresas brasileiras sob a perspectiva da resources-based view. REAd. Revista Eletrônica de Administração, v. 17, n. 2, p. 298-329, 2011.

OYADOMARI, J.C.; CARDOSO, R.L.; MENDONÇA NETO, O.R.; LIMA, M.P. Fatores que influenciam a adoção de artefatos de controle gerencial nas empresas brasileiras: um estudo exploratório sob a ótica da teoria institucional. Revista de Contabilidade e Organizações, v. 2, n. 2, p. 55-70, 2008.

PANUCCI FILHO, L.; ALMEIDA, L.B. A contabilidade gerencial no crescimento das organizações: um estudo nas indústrias de confecções. Revista Iberoamericana de Contabilidad de Gestión, v. 9, n. 18, 2011. Disponível em: <http://www.observatorioiberoamericano.org/RICG/N\%C2\%BA\%2018/Laurindo_Panuccci-

Filho_\%20Lauro_Brito.pdf $>$. Acesso em: 10 maio 2015.

PERERA, S.; BAKER, P. Performance measurement practices in small and medium size manufacturing enterprises in Australia. Small Enterprise Research, v. 15, n. 2, p. 10-30, 2007.

PERREN, L.; GRANT, P. The evolution of management accounting routines in small businesses: a social construction perspective. Management Accounting Research, v. 11, n. 4, p. 391-411, 2000.

PIRES, M.A.; COSTA, F.M.; HAHN, A.V. Atendimento das necessidades de informação para a tomada de decisão em pequenas e médias empresas: análise crítica das informações geradas pela contabilidade frente ao seus objetivos - pesquisa exploratória no setor de confecções da Glória - ES. In: SIMPÓSIO FUCAPE DE PRODUÇÃO CIENTÍFICA, 2., 2004, Vitória, Anais... Vitória: FUCAPE, 2004.

QUEIROZ, L.M.N. Investigação do uso da informação contábil na gestão das micro e pequenas empresas da Região do Seridó Potiguar. Brasília, 2005. 140f. Dissertação (Mestrado em Ciências Contábeis) - Programa Multiinstitucional e Inter-regional de Pósgraduação em Ciências Contábeis da UNB/UFPE/UFPB/UFRN, Universidade de Brasília, Brasília, 2005.

RUENGDET, K.; WONGSURAWAT, W. Characteristics of successful small and micro community enterprises in rural Thailand. Journal of Agricultural Education and Extension, v. 16, n. 4, p. 385-397, 2010.

SALES, R.L.; BARROS, A.A.; ARAÚJO, C.M.M.F. Fatores condicionantes da mortalidade dos pequenos negócios em um típico município interiorano brasileiro. Revista da Micro e Pequena Empresa, v. 2, n. 2, p. 38-55, 2011.

SANTANA, A.F.B.; CIUPAK, C.; KUHN, I.N.; TISOTT, S.T. Diagnóstico e análise da utilização da contabilidade gerencial nas micro, pequenas e médias empresas da cidade de Cruz Alta - RS. In: CONGRESSO BRASILEIRO DE CUSTOS, 14., 2007, João Pessoa. Anais... São Leopoldo: ABCustos, 2007. CD-ROM.

SANTOS, V.; BENNERT, P.; FIGUEIREDO, G.H.; BEUREN, I.M. Instrumentos da contabilidade gerencial utilizados pelas micro, pequenas e médias empresas: estudo em uma prestadora de serviços contábeis e seus respectivos clientes. In: CONGRESSO BRASILEIRO 
DE CUSTOS, 21., 2014, Natal. Anais... São Leopoldo: ABCustos, 2007. CD-ROM.

SANTOS, G.P.; ALVES, D.F.; BARRETO, M.O.R. A utilização da contabilidade de custos como ferramenta para o fortalecimento de uma micro empresa do segmento de confecção em Fortaleza. Revista Razão Contábil \& Finanças, v. 3, n. 1, p.1-12, 2012.

SERVIÇO BRASILEIRO DE APOIO ÀS MICRO E PEQUENAS EMPRESAS (SEBRAE). Fatores condicionantes e taxa de mortalidade de empresas no Brasil. Brasília, ago./2007.

SERVIÇO BRASILEIRO DE APOIO ÀS MICRO E PEQUENAS EMPRESAS (SEBRAE). Fatores condicionantes e taxa de mortalidade de empresas no Brasil. Brasília, out./2011.

SERVIÇO BRASILEIRO DE APOIO ÀS MICRO E PEQUENAS EMPRESAS (SEBRAE). Fatores condicionantes e taxa de mortalidade de empresas no Brasil. Brasília, jul./2013.

SERRASQUEIRO, Z.M.S.; NUNES, L. A informação contabilística na tomada de decisão dos empresários e/ou gestores. In: Congresso de Contabilidade, 10., 2004, Lisboa. Anais... Lisboa, 2004. CD-ROM.

SHAHABI, A.; HOSSEINPOUR, S.; SOHEILA, Z. An investigation into accounting practices of small and medium enterprises of Tehran Province in Iran. Reef Resources Assessment and Management Technical Paper, v. 40, n.5, p. 285-295, 2014.

SILVA, D.J.C.; MIRANDA, L.C.; FREIRE, D.R.; ANJOS, L.C.M. Para que serve a informação contábil nas micro e pequenas empresas? Revista Contemporânea de Contabilidade, v. 7, n. 13, p. 89-106, 2010.

SOUTES, D.O. Uma investigação do uso de artefatos da contabilidade gerencial por empresas brasileiras. 116f. Dissertação (Mestrado em Ciências Contábeis) - Universidade de São Paulo, São Paulo, 2006.

SOUZA, L. E. Fundamentos de contabilidade gerencial: um instrumento para agregar valor. Curitiba: Juruá, 2008.

STROEHER, A.M.; FREITAS, H. O uso das informações contábeis na tomada de decisão em pequenas empresas. Revista de Administração (eletrônica), São Paulo, v. 1, n. 1, p.1-25, 2008.

SULAIMAN, M.; AHMAD, N; NAZLI, N; ALWI, N. Management accounting practices in selected Asian countries: a review of the literature. Managerial Auditing Journal, v. 19, n. 4, p. 493-508, 2004.

ŠVÁROVÁ, M.; VRCHOTA, J. Strategic management in micro, small and medium-sized businesses in relation to financial success of the enterprise. Acta Universitatis Agriculturae et Silviculturae Mendelianae Brunensis, v. 61, n. 7, p. 2859-2866, 2013.

ZELENY, M. Multiple criteria decision making. New York: McGraw-Hill, 1982. 


\section{APÊNDICE - INSTRUMENTO DE PESQUISA}

\section{Perfil do respondente e da empresa}

\section{Perfil do respondente}

1.1 Gênero:

( ) Masculino ( ) Feminino

1.2 Qual a função que você ocupa na empresa?

1.3 Faixa de idade do entrevistado:
( ) Inferior a 25 anos
( ) Entre 26 e 30 anos
( ) Entre 31 e 35 anos
( ) Entre 36 e 40 anos
( ) Entre 41 e 50 anos
( ) Superior a 50 anos

1.4 Escolaridade:

( ) Ensino fundamental incompleto

( ) Ensino fundamental completo

( ) Ensino médio incompleto

( ) Ensino médio completo

( ) Ensino superior incompleto

( ) Pós-Graduação

( ) Ensino superior completo

( ) Outro. Qual?

Se assinalado ensino superior, qual a sua formação?

Se assinalado pós graduação, qual sua área de especialização?

1.5 Com que frequência você costuma realizar cursos de gestão?
( ) Frequentemente
( ) Raramente
( ) Com pouca frequência
( ) Outra. Qual?
( ) Nunca

\section{Perfil da empresa}

1.6 Como você classifica o ramo da empresa em que opera?
( ) Comércio varejista
( ) Indústria
( ) Comércio atacadista
( ) Outro. Qual?
( ) Serviços

1.7 Qual o faturamento bruto anual da empresa (em reais)?

1.8 Qual o número atual de funcionários da empresa?

1.9 Qual o regime de tributação de sua empresa?
( ) Simples Nacional
( ) Lucro Real
( ) Lucro Presumido
( ) Não conheço
( ) Lucro Arbitrado

1.10 Há quanto tempo a empresa foi constituída?
( ) Menos de 01 ano
( ) Entre 02 e 05 anos
( ) Entre 06 e 10 anos
( ) Entre 11 e 20 anos
( ) Entre 21 e 50 anos
( ) Acima de 50 anos 
1.11 Como você classifica o desempenho de seu negócio em comparação com seus concorrentes?
( ) Acima da média
( ) Na média
( ) Abaixo da média
( ) Não sei informar

\section{Tomada de decisão}

Este bloco objetiva identificar os procedimentos de tomada de decisão das micro, pequenas e médias empresas.

2.1 Atualmente, o comando/administração da empresa é exercido por quem?
( ) Proprietário/sócio da empresa
( ) Administrador contratado pela empresa
( ) Gerente
( ) Outro. Qual?

2.2 Quais os recursos que são mais utilizados para a tomada de decisão? (Marque todas que se aplicam)
( ) Experiência do empresário
( ) Informações fornecidas pela contabilidade
( ) Relatórios elaborados pelos gestores
( ) Outro. Qual?
( ) Intuição

2.3 Você tem conhecimento do resultado mensal (lucro ou prejuízo) da empresa?
( ) Sim
( ) Não

2.4 Qual a frequência que você discute o resultado da empresa junto ao seu contador?
( ) Frequentemente
( ) Com pouca frequência
( ) Raramente
( ) Nunca
( ) Outro. Qual?

2.5 Quem você consulta para tomar decisões financeiras? (Marque todas que se aplicam)
( ) Contador
( ) Consultor
( ) Economista
( ) Administrador
( ) Família
( ) Órgãos do governo
( ) Gerente do banco
( ) SEBRAE
sozinho
( ) Outro. Quem?

2.6 Quem é o responsável pelo setor financeiro (contas a receber e contas a pagar)?
( ) Proprietário/sócio da empresa
( ) Administrador contratado pela empresa
( ) Gerente
( ) Outro. Quem?

2.7 Quem é o responsável pelo controle da produção da empresa?
( ) Proprietário/sócio da empresa
( ) Administrador contratado pela empresa
( ) Gerente
( ) Outro. Quem?

2.8 Informações contábeis contribuem com os objetivos da empresa? (Marque todas que se aplicam)
( ) Sim, nas decisões diárias
( ) Sim, nas decisões estratégicas
( ) Sim, nas decisões de financiamento
( ) Sim, nas decisões de investimento
( ) Sim, no acompanhamento dos negócios e atendimento da parte legal
( ) Não quero opinar
( ) Outro. Qual?

2.9 Quais informações a sua empresa considera importantes para garantir a continuidade do negócio? (Marque todas que se aplicam) 
( ) Conhecer os custos do produto

( ) Conhecer os concorrentes

( ) Conhecer o valor de mercados dos produtos

( ) Possuir um bom planejamento tributário
( ) Conhecer o fluxo de caixa futuro

( ) Saber analisar o Balanço Patrimonial da empresa

( ) Conhecer a demanda do produto

( ) Outro. Qual?

2.10 Qual sistema é utilizado na elaboração de relatórios para decisão na empresa? (Marque todas que se aplicam)
( ) Manual (papel)
( ) Pacote multiusuário
( ) Planilha Excel
( ) Nenhum
( ) ERP
( ) Outro:

2.11 A contabilidade da sua empresa é utilizada como instrumento de apoio à gestão?

( ) $\operatorname{Sim}$

( ) Não

2.12 Se a resposta anterior for sim, explique de que forma você utiliza a contabilidade no apoio à gestão?

2.13 Se a resposta para a pergunta 2.11 for não, quais os fatores que dificultam/impedem a utilização da contabilidade no apoio à gestão? (Marque todas que se aplicam)
( ) Desconhece as utilidades
( ) Falta de comunicação com o contador
( ) Dificuldades para interpretar os relatórios
( ) Desacredita na contabilidade
( ) A informação contábil não reflete a real situação da empresa
( ) Outro. Qual?

\section{Instrumentos gerenciais utilizados pela empresa}

Este bloco objetiva verificar quais instrumentos de contabilidade gerencial são utilizados pelas micro, pequenas e médias empresas na tomada de decisão e quais são disponibilizados pelas prestadoras de serviços contábeis.

\begin{tabular}{|c|c|c|c|}
\hline \multirow[b]{2}{*}{ Instrumentos gerenciais } & \multicolumn{3}{|c|}{ Utiliza na tomada de decisão? } \\
\hline & Sim & $\begin{array}{l}\text { Conheço, mas } \\
\text { não utilizo }\end{array}$ & Desconheço \\
\hline Controle de caixa & $(\quad)$ & () & $(\quad)$ \\
\hline Controle de contas a pagar & () & () & () \\
\hline Controle de contas a receber & () & $(\quad)$ & () \\
\hline Controle de estoques & () & () & () \\
\hline Controle de custos e despesas & $(\quad)$ & () & () \\
\hline Balancete & () & () & () \\
\hline Balanço Patrimonial e Demonstração do Resultado do Exercício & () & () & () \\
\hline Demonstração do Valor Adicionado (DVA) & $(\quad)$ & () & () \\
\hline Demonstração dos Fluxos de Caixa (DFC) & () & () & () \\
\hline $\begin{array}{l}\text { Demonstração das Mutações do Patrimônio Líquido (DMPL) e } \\
\text { Demonstração dos Lucros ou Prejuízos Acumulados (DLPA) }\end{array}$ & $(\quad)$ & () & () \\
\hline Notas explicativas & $(\quad)$ & () & $(\quad)$ \\
\hline $\begin{array}{l}\text { Custeio por absorção - consiste na apropriação de todos os custos da } \\
\text { produção aos bens elaborados }\end{array}$ & $(\quad)$ & () & $(\quad)$ \\
\hline $\begin{array}{l}\text { Custeio variável - consiste em considerar como custo da produção } \\
\text { apenas os custos variáveis incorridos }\end{array}$ & $(\quad)$ & $($ ) & $($ ) \\
\hline $\begin{array}{l}\text { Custeio padrão - a ideia principal consiste em determinar o que seria } \\
\text { o custo padrão para a produção de um determinado período e, ao fim } \\
\text { do período, apurar os custos reais, a fim de compará-los }\end{array}$ & $(\quad)$ & $($ ( ) & $(\quad)$ \\
\hline $\begin{array}{l}\text { Custeio baseado em atividades }(\mathrm{ABC}) \text { - sistema de custeamento que } \\
\text { considera a acumulação dos custos a partir das atividades } \\
\text { empresariais }\end{array}$ & () & () & $(\quad)$ \\
\hline
\end{tabular}


Custo meta - usado quando o preço de venda de determinado produto é definido pelo mercado, cabe à empresa então o processo de determinação do custo máximo permitido para aquele produto objetivando o lucro desejado.

Retorno sobre o investimento - consiste em expressar a rentabilidade do investimento em termos absolutos

Orçamento - um plano detalhado para o futuro, geralmente expresso em termos quantitativos.

Planejamento tributário - forma, dentro da lei, de diminuir o pagamento de tributos.

Cálculo do ponto de equilíbrio - nível de vendas onde o lucro é igual a zero

Planejamento estratégico - seleção de uma linha de ação e especificação de como esta ação será posta em prática.

\begin{tabular}{|c|c|c|}
\hline$(\quad)$ & $($ ) & ( ) \\
\hline$(\quad)$ & () & ( ) \\
\hline$(\quad)$ & ( ) & ( ) \\
\hline ( ) & ( ) & ( ) \\
\hline ( ) & ( ) & ( ) \\
\hline ( ) & ( ) & ( ) \\
\hline
\end{tabular}

Há algum outro instrumento que você utiliza para a tomada de decisões? ( ) Sim ( ) Não. Se sim, Qual?

\section{Importância atribuída pelas empresas aos instrumentos de contabilidade gerencial}

Este bloco objetiva identificar a importância atribuída aos instrumentos de contabilidade gerencial pelos gestores de micro, pequenas e médias empresas. Classifique o grau de importância de cada instrumento gerencial listado a seguir na administração da sua empresa.

\begin{tabular}{|c|c|c|c|c|c|}
\hline Instrumentos gerenciais & $\begin{array}{c}\text { Nada } \\
\text { importante }\end{array}$ & $\begin{array}{c}\text { Pouco } \\
\text { importante }\end{array}$ & Indiferente & Importante & $\begin{array}{c}\text { Muito } \\
\text { importante }\end{array}$ \\
\hline \multicolumn{6}{|l|}{ Controles operacionais } \\
\hline Controle de caixa & () & $(\quad)$ & $(\quad)$ & $(\quad)$ & $(\quad)$ \\
\hline Controle de contas a pagar & () & () & () & () & () \\
\hline Controle de contas a receber & () & () & () & () & () \\
\hline Controle de estoques & () & () & () & () & () \\
\hline Controle de custos e despesas & () & $(\quad)$ & () & () & () \\
\hline \multicolumn{6}{|l|}{ Demonstrações contábeis } \\
\hline Balancete & () & () & () & () & () \\
\hline $\begin{array}{l}\text { Balanço Patrimonial e Demonstração do } \\
\text { Resultado do Exercício }\end{array}$ & $($ ) & $(\quad)$ & ( ) & $($ ( ) & $(\quad)$ \\
\hline $\begin{array}{l}\text { Demonstração do Valor Adicionado } \\
\text { (DVA) }\end{array}$ & $(\quad)$ & ( ) & ( ) & ( ) & ( ) \\
\hline $\begin{array}{l}\text { Demonstração dos Fluxos de Caixa } \\
\text { (DFC) }\end{array}$ & $($ ( ) & ( ) & ( ) & ( ) & ( ) \\
\hline $\begin{array}{l}\text { Demonstração das Mutações do } \\
\text { Patrimônio Líquido (DMPL) e } \\
\text { Demonstração dos Lucro ou Prejuízos } \\
\text { Acumulados (DLPA) }\end{array}$ & $($ ） & $(\quad)$ & ( ) & ( ) & $(\quad)$ \\
\hline Notas explicativas & () & $(\quad)$ & $(\quad)$ & $(\quad)$ & $(\quad)$ \\
\hline \multicolumn{6}{|l|}{ Métodos de custeio } \\
\hline Custeio por absorção & $(\quad)$ & $(\quad)$ & $(\quad)$ & () & $(\quad)$ \\
\hline Custeio variável & () & () & $(\quad)$ & $(\quad)$ & $(\quad)$ \\
\hline Custeio padrão & () & () & () & () & () \\
\hline Custeio baseado em atividades (ABC) - & $(\quad)$ & () & $(\quad)$ & $(\quad)$ & () \\
\hline Custo meta & () & () & $(\quad)$ & () & $(\quad)$ \\
\hline \multicolumn{6}{|l|}{ Outros artefatos } \\
\hline Retorno sobre o investimento & $(\quad)$ & $(\quad)$ & $(\quad)$ & $(\quad)$ & $(\quad)$ \\
\hline Orçamento & $(\quad)$ & $(\quad)$ & $(\quad)$ & $(\quad)$ & () \\
\hline Planejamento tributário & $(\quad)$ & $(\quad)$ & () & $(\quad)$ & $(\quad)$ \\
\hline Cálculo do ponto de equilíbrio & $(\quad)$ & $(\quad)$ & $(\quad)$ & () & $(\quad)$ \\
\hline Planejamento estratégico & () & $(\quad)$ & () & () & $(\quad)$ \\
\hline
\end{tabular}

